\title{
Spectral Decomposition of Regulatory Thresholds for Climate-Driven Fluctuations in Hydro- and Wind Power Availability \\ DOI:
}

10.1002/2017WR020460

\section{Document Version}

Accepted author manuscript

Link to publication record in Manchester Research Explorer

Citation for published version (APA):

Wörman, A., Bottacin Busolin, A., Zmijewski, N., \& Riml, J. (2017). Spectral Decomposition of Regulatory Thresholds for Climate-Driven Fluctuations in Hydro- and Wind Power Availability. Water Resources Research, 53(8), 7296-7315. https://doi.org/10.1002/2017WR020460

\section{Published in:}

Water Resources Research

\section{Citing this paper}

Please note that where the full-text provided on Manchester Research Explorer is the Author Accepted Manuscript or Proof version this may differ from the final Published version. If citing, it is advised that you check and use the publisher's definitive version.

\section{General rights}

Copyright and moral rights for the publications made accessible in the Research Explorer are retained by the authors and/or other copyright owners and it is a condition of accessing publications that users recognise and abide by the legal requirements associated with these rights.

\section{Takedown policy}

If you believe that this document breaches copyright please refer to the University of Manchester's Takedown Procedures [http://man.ac.uk/04Y6Bo] or contact uml.scholarlycommunications@manchester.ac.uk providing relevant details, so we can investigate your claim.

\section{OPEN ACCESS}




\section{Spectral Decomposition of Regulatory Thresholds for Climate-Driven}

\section{Fluctuations in Hydro- and Wind Power Availability}

Wörman, A. ${ }^{1, *}$, Bottacin-Busolin, A. ${ }^{2}$, Zmijewski, N. $^{1}{ }^{10}$, Riml, J. ${ }^{1}$

*Corresponding author, worman@kth.se

${ }^{1}$ The Royal Institute of Technology, Division of River Engineering, 10044 Stockholm,

Sweden

${ }^{2}$ The University of Manchester, School of Mechanical, Aerospace and Civil Engineering, Manchester M13 9PL, United Kingdom

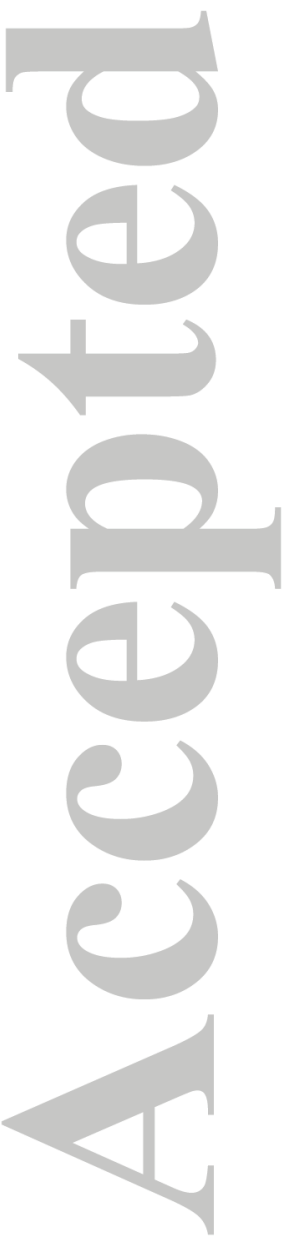

This article has been accepted for publication and undergone full peer review but has not been through the copyediting, typesetting, pagination and proofreading process which may lead to differences between this version and the Version of Record. Please cite this article as an 'Accepted Article', doi: 10.1002/2017WR 020460 


\section{Abstract}

Climate-driven fluctuations in the runoff and potential energy of surface water are generally large in comparison to the capacity of hydropower regulation, particularly when hydropower is used to balance the electricity production from covarying renewable energy sources such as wind power. To define the bounds of reservoir storage capacity, we introduce a dedicated reservoir volume that aggregates the storage capacity of several reservoirs to handle runoff from specific watersheds. We show how the storage bounds can be related to a spectrum of the climate-driven modes of variability in water availability and to the co-variation between water and wind availability. A regional case study of the entire hydropower system in Sweden indicates that the longest regulation period possible to consider spans from a few days of individual sub-watersheds up to several years, with an average limit of a couple of months. Watershed damping of the runoff substantially increases the longest considered regulation period and capacity. The high covariance found between the potential energy of the surface water and wind energy significantly reduces the longest considered regulation period when hydropower is used to balance the fluctuating wind power. 


\section{Introduction}

Because renewable energy, such as solar power, wind power and hydropower, is intermittent in character, balancing the increasing amounts of electricity from renewable sources under climate variability (Korpås et al., 2013) while complying with policy directives (2000/60/ec; 2009/28/ec) is a significant challenge for the future. The availability of renewable energy sources, such as solar, wind and hydropower, shows coherences over long periods (Wörman et al., 2017), which stresses the need for regulation strategies. Our preparedness for adopting renewable energy production relies on understanding the nexus between climatic drivers and regulatory capacity, particularly in hydropower due to its potential for storing energy in water reservoirs (Guégan et al., 2012; Hamadu and Killingtveit, 2012). Energy storage in hydropower reservoirs can be used both for conventional hydropower with regulation of the inflow to the reservoir and by pump storage (Endegnanew et al., 2013), which provides important regulatory capacity in addition to a runof-the-river production scheme. Such storage is useful in particular because of the increasing contributions to electricity generation from different intermittent renewable energy sources, such as wind- and hydropower, which can produce new demands for the long-term regulatory capacity, either from the use of non-renewable energy sources or from the limits of the reservoir storage capacity in hydropower systems. The combined reservoir capacity of the Scandinavian countries represents approximately $70 \%$ of the total reservoir capacity available in Europe (World Energy Outlook, 2015). The energy stored in these reservoirs can be a major resource for balancing short-term fluctuations in renewable electricity production.

Estimating the reservoir capacity needed to balance the intra- and inter-annual variability of the inflows and the water demand is a vital task. Reservoir sizing can be performed in various ways, including the use of flow duration curves, the Rippl method (1883), the sequent peak method (Thomas and Burden, 1963; Vogel and Stedinger, 1987; Vogel, 1988), the least 
marginal environmental impact rule (LMEI) (Takeuchi, 1997) or various simulation and optimization approaches based on either records or a synthetic time series of the inflow (see e.g., Loucks and Va Beek, 2005). Recently, Geressu and Harou (2016) proposed an optimized multi-criteria screening approach for identifying the best performing designs of new reservoirs within multi-reservoir systems. However, none of these methods explicitly account for fluctuations or trends in the regulatory demand or water availability, thereby reducing the reliability of the design over longer time scales.

A number of studies have investigated the impact of climate change on hydropower production (Ely et al., 2013; Farahmand, eta 1., 2015). Block and Strzepek (2010) and Suomalainen et al. (2015) presented an economic analysis of the large-scale upstream river basin development on the Blue Nile in Ethiopia and concluded that climate variability and climate change have significant implications for the planning of water resources systems. Lanini et al. (2014) examined the variability of hydropower generation and reservoir operations and their relation to a stochastic ensemble of reservoir inflows reflecting different climate change scenarios. Gaupp et al. (2015) used the sequent peak method for investigating how much storage would be needed to satisfy human water demand while not jeopardizing environmental flows in 403 of the most important river basins. They concluded that several basins would require more storage to mitigate the water supply variability and meet water demand. Giuliani et al. (2016) analyzed the role of large storage operations as a flexible means of adaptation to climate change and found that the adverse impact of climate change can be partially mitigated by adapting existing operations to future climate scenarios.

For large multi-reservoir systems, the coordination of reservoir operations can also significantly affect the efficiency of water management practices. Jeuland et al. (2014) analyzed the costs of uncoordinated infrastructure management in multi-reservoir river basins and found that coordination improves the system net benefits of irrigation and hydropower. 
The role of coordination is likely to be even more significant when hydropower is used for power load balancing, i.e., to compensate for the production fluctuation in one energy source by the corresponding fluctuation in the hydropower production. Recently, Fernandez et al. (2013) have investigated the feasibility of using hydropower as a balancing source of energy for wind power. They found that the hydropower facilities would face significant policy conflicts if asked to store and release water to accommodate wind integration.

The aim of this study is to analyze the regulatory limit or threshold of the Swedish reservoir system, particularly defined as a ratio of the maximum water volume storage in hydropower reservoirs and the climate-driven fluctuations in water volume availability used for energy production. The water volume storage capacity can also be expressed in terms of energy storage capacity. Because the water energy availability varies over different time frequencies that are typical of the climate system, a particular aim is to derive a methodology that allows for the decomposition of the frequency in the regulatory capacity and the accounting of the correlation between water availability and other climate indices. This derivation is performed to define the regulatory capacity limit statistically as a function of the maximum period possible to consider in energy regulation. A basic scenario for the regulation objective is a constant production scheme, but other scenarios comprise the balancing of fluctuating wind power production. These balancing scenarios are anticipated because of the transition toward a future renewable energy system where wind power is likely to be a major component (Olausson et al., 2016). A particular focus is an analysis of how the hydropower production demand is affected by the coherence between wind- and hydropower availability when hydropower is used as a balancing source of energy for wind power. This study provides an example of the regulatory threshold of the entire hydropower and reservoir system of Sweden based on the available runoff and a wind intensity time series with national coverage. 
2. Methods

\subsection{Regional hydro-climatic and hydropower data and scenarios for regulatory analyses}

The analysis of the regulatory capacity of the Swedish reservoir system was based on a spatial scope of 1,001 sub-watersheds that cover the whole surface of Sweden including minor parts of Norway and Finland, with areas ranging from 14.7 to $9,791 \mathrm{~km}^{2}$, the mean area is $4,699 \mathrm{~km}^{2}$, and the coefficient of variation is 1.16 . Fig. 1 shows the sub-watersheds, for which the runoff power potential and the available power at all existing hydropower stations were determined with a daily resolution between 1961 and 2011 (51 years), as described in a previous work (Wörman, et al., 2017). The actual production at the hydropower stations was estimated based on the reported fall height (head) at the hydropower stations. It was assumed that this fall height was available for all the water passing through a sub-watershed or only for a fraction of the internal runoff of the sub-watershed. The description of the hydropower system included the production data for 506 hydropower stations, their maximum fall height, and a total reservoir volume of $49,841 \times 10^{6} \mathrm{~m}^{3}$, which was distributed among 303 of the 1,001 sub-watersheds. As a whole, the actual annual production of the considered hydropower stations was $65.06 \mathrm{TWh} / \mathrm{y}$ over the period for which monthly data of electricity production were available, i.e., January 1974 to December 2013. These production data were obtained from the Swedish Energy Authority as an aggregate set of power production units. The normal production declared by the owners of the hydropower stations considered was $65.5 \mathrm{TWh} / \mathrm{y}$. Therefore, even if the actual production of the individual stations is unknown, we can assume that nearly $100 \%$ of all of the hydropower production is represented in this study. 
The regulatory analysis considers a fluctuating demand or production discharge, $D\left(\mathrm{~m}^{3} / \mathrm{s}\right)$; the inflow of available water, $q\left(\mathrm{~m}^{3} / \mathrm{s}\right)$; and the corresponding fluctuation in the assigned storage volume, $V\left(\mathrm{~m}^{3}\right)$ as given by the continuity equation $\partial V / \partial t=q-D$. Therefore, the demanded reservoir volume $\Delta V_{\mathrm{B}}\left(\mathrm{m}^{3}\right)$ is proportional to the total interval or bounds of the assigned storage volume. The administration and mathematical linkage of the available water and assigned reservoir volume for the 1,001 watersheds used in the analysis are described in more detail in Sections 2.2 and 2.3. Furthermore, this study considers two scenarios for the regulation analysis:

1. the production discharge $D$ required to satisfy the demand is constant, and

2. the production discharge $D$ required to satisfy the demand is fluctuating to balance the fluctuations in wind power availability.

The first scenario (1) is used as a baseline scenario for the regulatory or reservoir volume bounds and to determine the spatial variance in the regulatory capacity and the effect of spatial coordination. The assigned storage volume is compared with the dedicated reservoir volume (DRV, see Section 2.3) for each of the 1,001 sub-watersheds, which is a constant reservoir volume setting that limits for the storage that can be accommodated. The ratio of the assigned storage volume bounded to the dedicated reservoir volume, $\Delta V_{\mathrm{B}} / V_{\mathrm{DRV}}$, yields a relevant measure of the relative capacity and regulatory bounds, where $V_{\mathrm{DRV}}=$ dedicated reservoir volume $\left(\mathrm{m}^{3}\right)$. The second scenario (2) is expressed in a simplified form in Section 2.5 to facilitate an estimation of the regulatory needs related to the coordination between wind- and hydropower production. The future wind power scenarios used in this study are primarily based on those developed by Olauson et al. (2016), which consider an expanded wind power production from the current level of $17 \mathrm{TWh} / \mathrm{y}$ to 20,30 and $50 \mathrm{TWh} / \mathrm{y}$. The model was developed by Olauson and Bergqvist, 2015) based on the data of Riecker et al. (2011) and the Swedish power system for the expansion of wind power distributed on 
numerous wind power plant locations. The background for the wind power expansion scenarios is the global and Swedish political direction toward a transition to renewable energy systems. The EU's Renewable Energy Directive sets a binding target of $20 \%$ for the final energy consumption from renewable sources by 2020 , which includes a target of $49 \%$ in

Sweden. In comparison, the US Department of Energy has presented a scenario for wind power production in which $35 \%$ of the total electricity consumption is produced by wind power by 2050 (US DOE, 2015).

To reveal the cross-correlation between the available power of runoff and wind power, we used the annual and daily data of the geostrophic wind velocity obtained from the Swedish Meteorological and Hydrological Institute (SMHI), with national coverage from 1951. These data had full coverage of Sweden and was only used for this statistical assessment, whereas the wind power scenarios - although related to the geostrophic wind data - were obtained independently for the assumed distribution of wind power plants as described above. Geostrophic wind is a derived quantity based on observations of air pressure, air density and latitude to provide a theoretical Coriolis force. The calculations were performed for nine triangles with national coverage, and an arithmetic mean calculated based on these nine triangles (Wern and Berring, 2009).

\subsection{Spectral regulatory analysis -The temporal decomposition of the problem}

As mentioned, the fluctuation in the assigned storage volume associated with the inflow $q_{i}$ to a reservoir with storage $V_{i}$ associated with the individual sub-watershed $i$ is given by the continuity equation $\partial V_{i} / \partial t=q_{i}-D_{i}$. The demanded outflow discharge $D_{i}$ is related to the hydropower production, which, in turn, depends on a variety of factors. The power spectral form of the continuity equation can be evaluated by taking the Fourier transform and multiplying by its complex conjugate, which yields 
$\omega^{2} P_{V, i}(\omega)=P_{q, i}(\omega)+P_{D, i}(\omega)-2 \operatorname{Re}\left\{P_{q, D, i}(\omega)\right\}$

where $P_{V, i}\left(m^{6} s^{2}\right) P_{q, i}\left(m^{6}\right)$ and $P_{D, i}\left(m^{6}\right)$ denote the power spectra of $V_{i}, q_{i}$, and $D_{i}$,

respectively; $P_{q, D, i}$ is the cross-power spectrum of $q_{i} ; D_{i}, \omega=1 / T_{f}\left(s^{-1}\right)$ is the frequency; $T_{f}$ is the period(s); and Re denotes the real part evaluation. The short derivation of Eqn. (1) involves two cross-spectrum terms that mirror each other in the imaginary domain and therefore cancel out, hence leading to Eqn. (1). This equation is fundamental to the analysis proposed here since it i) decomposes the contribution to the regulatory volume demand on frequencies considered in the regulation, and ii) separates the spectral contribution on the water availability, production discharge and their cross-correlation, and iii) facilitates a statistical incorporation of climate effects on water availability expressed in the form of $\mathrm{P}_{\mathrm{q}, \mathrm{i}}$ (Wörman et al., 2017). Specifically, the equation is useful for expressing the variance in the assigned reservoir volume by using the following equalities:

$$
\operatorname{Std}^{2}\left(V_{i}\right)=\frac{1}{(2 \pi)} \int_{-\pi}^{\pi} P_{V, i}(\omega) d \omega=\frac{1}{T_{2}-T_{1}} \int_{T_{f}=T_{1}}^{T_{2}} \frac{P_{V, i}\left(T_{f}\right)}{T_{f}^{2}} d T_{f}=\int_{T_{f}=T_{1}}^{T_{2}} \frac{S_{V, i}\left(T_{f}\right)}{T_{f}^{2}} d T_{f}
$$

where $S_{V}$ is the power spectral density of $V\left(\mathrm{~m}^{6} \mathrm{~s}\right)$, and $S t d$ is the standard deviation operator. Note that this expression does not consider the actual limitations on the available reservoir volume. Because $\omega^{2} P_{V, i}(\omega)=P_{V, i}\left(T_{f}\right) / T_{f}^{2}$, Eqns. (1) and (2) imply that the reservoir volume variance can be integrated over the variances in the reservoir inflows and demand in the form

$$
\operatorname{Std}^{2}\left(V_{i}\right)=\int_{T_{f}=T_{1}}^{T_{2}}\left(S_{q, i}\left(T_{f}\right)+S_{D, i}\left(T_{f}\right)-2 S_{q, D, i}\left(T_{f}\right)\right) d T_{f}
$$


where $S_{q}$ and $S_{D}$ are the power spectral densities ( $\left.\mathrm{m}^{6} / \mathrm{s}\right), d T_{f} / d \omega=-2 \pi / \omega^{2}$ and $i=1,2 \ldots N$, and $\mathrm{N}=$ number of watersheds. Consequently, this means that the variance in the regulatory volume increases continuously with the upper period $T_{2}$ considered in the regulation. A limiting regulatory case can be defined for an assumed constant demand discharge in scenario 1 (Section 2.1), i.e., $S_{D, i}=S_{q, D, i}=0$, which leads to a simple relationship between the power spectral density of runoff and the variance in the required reservoir volume

$S t d^{2}\left(V_{i}\right)=\int_{T_{f}=T_{1}}^{T_{2}}\left(S_{q, i}\left(T_{f}\right)\right) d T_{f}$

The interval (bounds) of a uniform distribution of storage volume $V_{i}$ can be defined as $\Delta V_{B, i}=2 \max \left(V_{i}-\mu_{V, i}\right)$, which can easily be rewritten in the form $\left(\Delta V_{B, i}\right)^{2}=12 \sigma_{V_{i}}^{2}$, where $\mu_{V, i}$ is the expected value of the storage volume, and $\sigma_{V, i}^{2}$ is the variance of the storage, i.e., $S t d^{2}\left(V_{i}\right)=\sigma_{V, i}^{2}$. For an unbounded distribution, e.g., Gaussian, the bounds of the storage variation are linearly proportional to the standard deviation in the storage $V_{B, i}$, but they also depend on the exceedance probability of the bounds in the form of (Zmijewski and Wörman, 2016)

$\Delta V_{B, i}^{2}=a S^{2} d^{2}\left(V_{i}\right)=a \int_{T_{f}=T_{1}}^{T_{2}} \frac{S_{V, i}\left(T_{f}\right)}{T_{f}^{2}} d T_{f}$

where $a(p)$ is a proportionality coefficient that depends on the probability $(1-p)$ that $V_{i}$ exceeds the bounds (exceedance probability) of the distribution of $V_{i}$, and $p$ is the quantile. For an unbounded distribution, we can use the cumulative distribution function of $V_{i}$ to define the coefficient $a=z_{p}{ }^{2}$, where $z_{p}$ is the upper (positive) p-quantile associated with the exceedance probability (1-p). For the standard normal (Gaussian) distribution, we have $p\left(\left(V_{i}-\mu_{V, i}\right) / \sigma_{V, i}<z_{p}\right)=1 / 2\left[1-\operatorname{erf}\left(z_{p} / \sqrt{2}\right)\right]$, where $\left(V_{i}-\mu_{V, i}\right) / \sigma_{V, i} \in N(0,1)$ and erf denotes the error function. For instance, $z_{p}=1$ (i.e., $\left.\Delta V_{i}=\sigma_{V, i}\right)$ corresponds to an exceedance probability of the upper bound of $15.87 \%$ for the normal distribution. 
An implication of Eqn. (5) is that the requested storage interval increases with a lowering of the exceedance probability and an increasing upper period $T_{2}$ considered for regulation.

The latter characteristics of the regulation problem occur because a continuous power spectral density function is always positive and, hence, the cumulative function on the right-hand side of Eqn. (5) increases monotonically with $T_{2}$. By using Eqns. (3) and (5), we can express the bounds of the storage variation as a function of the power spectral density of the discharge from sub-watershed, $\mathrm{i}$, in the form of

$$
\Delta V_{B, i}^{2}=z_{p}^{2} \int_{T_{f}=T_{1}}^{T_{2}}\left(S_{q, i}\left(T_{f}\right)+S_{D, i}\left(T_{f}\right)+2 S_{q, D, i}\left(T_{f}\right)\right) d T_{f}
$$

The relative simplicity of Eqn. (6) reflects that the runoff from individual sub-watersheds is treated as an independent regulatory problem without mutual coordination and to which the reservoir volumes are allocated or dedicated separately. Because the bounds of the storage variation are defined as $\Delta V_{B, i}=2 \max \left(V_{i}-\mu_{V, i}\right)$, Eqn. (6) also provides an estimate of the Reservoir Volume Demand (RVD) $V_{R V D, i}=\Delta V_{B, i}\left(\mathrm{~m}^{3}\right)$, i.e., the reservoir volume demanded specifically for the runoff from watershed $i$. The next section addresses how to allocate or dedicate the reservoir volume $V_{D R V, i}\left(\mathrm{~m}^{3}\right)$ along the flow path downstream of sub-watershed $i$. Particularly, the ratio $R_{R V D}=\Delta V_{R V D, i} / V_{D R V, i}$ offers an estimate of the relative reservoir volume demand in comparison to the dedicated volume. To facilitate the representation of the analysis results, it is convenient to define the standard storage bounds $\Delta V_{B, i}\left(z_{p}=1\right)$, which yield the relative regulatory volume demand in the form

$R_{R V D, i}=\frac{\Delta V_{R V D, i}}{V_{D R V, i}}=z_{p} \frac{\Delta V_{B, i}\left(z_{p}=1\right)}{V_{D R V, i}}=z_{p} R_{S-R V D, i}$

where the standardized relative RVD is defined as $\mathrm{R}_{\mathrm{S}-\mathrm{RVD}}=\Delta V_{B, i}\left(z_{p}=1\right) / V_{D R V, i}$. This standardization facilitates the generalization to various exceedance probabilities of the storage bounds. By inserting Eqn. (6) in Eqn. (7), one obtains the spectral form of the relative RVD 
$R_{R V D, i}\left(T_{2}\right)=z_{p} R_{S-R V D, i}\left(T_{2}\right)=z_{p} \frac{\sqrt{\int_{T_{f}=T_{1}}^{T_{2}}\left(S_{q, i}\left(T_{f}\right)+S_{D, i}\left(T_{f}\right)+2 S_{q, D, i}\left(T_{f}\right)\right) d T_{f}}}{V_{D R V, i}}$

The relative RVD increases monotonically with the upper integration limit $T_{2}$, hence, providing a spectral representation of the standardized relative RVD. The ensemble of $R_{S}$ ${ }_{R V D}\left(T_{2}\right)$ spectra for all the 303 sub-watersheds with the DRV is used to derive an ensemble mean to reflect the national average storage capacity.

\subsection{Dedicated Reservoir Volume (DRV) - The spatial decomposition of the problem}

To provide a systematic comparison of the regulatory capacity, we identify the dedicated reservoir yolume (DRV), $V_{D R V}\left(\mathrm{~m}^{3}\right)$, for the runoff from each of the sub-watersheds and it is allocated as an aggregation of volumes from all of the downstream reservoirs in proportion to the runoff from watershed $i$. This means that the DRV is constant over time. Such a dedicated allocation and aggregation of storage implies a limitation of the regulation flexibility because a particular DRV handles runoff from a specific watershed and is not used to regulate runoff from other watersheds that feed water through that reservoir, which instead has another DRV from the same reservoir. An advantage of the DRV approach is that it allows for the identification of the lower bounds of the regulatory capacity, in which the runoff from each watershed is regulated independently from the runoff of other watersheds, hence, neglecting possible gains from the coherence in the runoff from different watersheds. Additionally, the upper bound of the regulatory capacity can be identified by theoretically aggregating the watersheds, whereby the increasing size of the watershed reflects the coordination gains due to the coherence in the runoff from the aggregated watersheds.

For DRV identification, the connectivity between the 1,001 sub-watersheds and flow paths to the sea was established for the identification of the flow pathways. For each reservoir $R$, the mean discharge $Q_{R, j}$ originating from each watershed $j$ was determined, and the storage 
associated with watershed $i$ was defined as $\mathrm{V}_{\mathrm{R}, \mathrm{i}}=\mathrm{v}_{\mathrm{R}} \alpha_{\mathrm{R}, \mathrm{i}}$, where the proportion $\alpha_{\mathrm{R}, \mathrm{i}}=$ $\left(\mathrm{Q}_{\mathrm{R}, \mathrm{i}} / \sum_{\mathrm{j}=1}^{\mathrm{K}} \mathrm{Q}_{\mathrm{R}, \mathrm{j}}\right), Q_{R, i}$ is the mean outflow discharge originating from watershed $i$ passing reservoir $R, v_{R}$ is the volume of reservoir $R$, and $K$ is the number of flow paths passing the reservoir $R$ (Fig. 1). The dedicated reservoir volume for the runoff originating from watershed $i$ was defined as $\mathrm{V}_{\mathrm{DRV}, \mathrm{i}}=\sum_{\mathrm{R}=1}^{\mathrm{M}} \mathrm{V}_{\mathrm{R} . \mathrm{i}}$, where $\mathrm{M}$ is the number of reservoirs that are passed by the outflow from watershed $i$ (Fig. 2).

\subsection{Watershed damping of the runoff variability and coherence of runoff}

In this study, we use simulated runoff data with complete national coverage based on the observations of precipitation from 650 gauges and stream discharge from 198 gauges. While this approach provides a detailed spatial and temporal resolution of the regulation problem for over half a century, there is still a need to relate the runoff data $r_{i}\left(\mathrm{~m}^{3} / \mathrm{s}\right)$ from each of the sub-watersheds $i$ to the inflow $q_{i}$ to reservoirs dedicated to the downstream flow path. Runoff is derived from the above mentioned data series (Wörman et al., 2017) and is referred to here as all the rainfall and snowmelt minus evapotranspiration that starts its travel generally through infiltration into groundwater and reaches the stream system where the water may flow into reservoirs after some additional travel. This translation of runoff to inflow is performed by expressing the reservoir inflow as a convolution between runoff, $r_{i}$, and the catchment instantaneous unit hydrograph (IUH), $\psi_{i}$, so that $q_{i}=r_{i}^{*} \psi_{i}$. Because the corresponding power spectral form can be expressed as $S_{q, i}=S_{r, i} S_{\psi, i}$, we can represent the variance in the storage for constant demand $D$ (Scenario 1, Section 2.1)

$$
\operatorname{Std}^{2}\left(V_{T o t, i}\right)=\int_{T_{f}=T_{1}}^{T_{2}}\left(S_{r, i}\left(T_{f}\right) S_{\psi, i}\left(T_{f}\right)\right) d T_{f}
$$

where $S_{\psi}$ is the square of the modulus of the Fourier transform of the IUH, which is referred to as a "scaling function" for the watershed (Riml and Wörman, 2015; Åkesson et al., 2016), 
and $i=1,2, \ldots N$. Furthermore, the relative RVD under constant demand $D$ is obtained by combining Eqns. (5), (7) and (9)

$R_{R V D, i}\left(T_{2}\right)=z_{p} \frac{\sqrt{\int_{T_{f}=T_{1}}^{T_{2}}\left(S_{r, i}\left(T_{f}\right) S_{\psi, i}\left(T_{f}\right)\right) d T_{f}}}{V_{D R V, i}}$

where the second factor (the fraction) on the right-hand side of Eqn. (10) is the standardized relative $\mathrm{RVD}$, i.e., $\mathrm{R}_{\mathrm{S}-\mathrm{RVD}}$.

Figure 3 shows the power spectral densities of the discharge at the effluences of a small sub-watershed of $1,103 \mathrm{~km}^{2}$ in the Dalälven River Basin at the Ersbo gauging station (red curve) and a larger sub-watershed of $25,058 \mathrm{~km}^{2}$ further downstream at the Fäggeby gauging station (Långhag hydropower station) (dark blue curve); the corresponding scaling function is $S_{\psi, i}=S_{q, i} / S_{r, i}$. The yellow curve in the background in Figure 3 shows the scaling function based on the hydrographs at Ersbo and Fäggeby before regulation commenced. . The fact that the scaling function generally falls below one implies that the hydrograph variability is increasingly damped with a decreasing period, i.e., $S_{\psi, i}$ decreases with a decreasing period. Most of this damping occurs within the relatively small sub-watersheds used in this study, which is because the damping along the main river channels is limited to time scales of up to approximately 100 hours (Zmijewski and Wörman, 2016; see Fig. 4). Consistently, the power spectral density of the hydrograph at the Gråda hydropower station between Ersbo and Fäggeby with a watershed size of $12,270 \mathrm{~km}^{2}$ more or less coincides with that of Fäggeby. In contrast, the hydrographs obtained from the regulated periods deviate significantly from pristine conditions, which is demonstrated by the spectral density of the hydrograph at Fäggeby after 1921 (blue-grayish curve in Fig. 3). Because the damping occurs on a small scale and the dedicated reservoir volumes are distributed along the main river channels with mostly short-term damping in-between, we decided to use one single scaling function (a single IUH) $S_{\psi, i}$ for all sub-watersheds, as represented in Fig. 3. The short-term damping (< 
$100 \mathrm{~h}$ ) is not of primary importance for the regulatory limits of the DRV, as shown in the following section.

\subsection{Discharge demand spectrum related to wind power fluctuations}

In this research, hydropower is committed to balancing the fluctuation in wind power and, specifically, wind power is assumed to dominate the power spectral density of the regulatory demand. From Eqn. (3), it is clear that the coherence spectrum between the reservoir inflow and the demand for hydropower production (third term on the right-hand side) may increase the variance in the reservoir storage, but it can also contribute to reducing the regulatory need to overcome storage limitations. A focus here is to study the regulatory capacity of the Swedish reservoir system when the hydropower production is governed by balance demands from the fluctuation in wind power production. In all the scenarios analyzed here, we neglect the possible covariance between the demand discharge and the reservoir inflow (water availability), i.e., the cross-spectral density $S_{q, D, i}$ in Eqn. (3) is zero, but the demand spectral density $\mathrm{S}_{\mathrm{D}, \mathrm{i}}$ varies because of the changing demand in balancing hydropower due to the different wind intensities. These scenarios apply if the cross-spectrum is very low or if the cross-correlation is difficult to account for in the regulation management, which is further discussed in Sections 3.4 and 4. Therefore, the regulatory demand relates to the need to match precisely the spectral densities in the wind power production $P_{W}(W)$ with the corresponding spectral densities in the balancing hydropower demand $P_{D, W, i}(W)$, which are expressed in the form of their spectral densities $S_{P, W, i}=S_{P, D, I}$, where $S_{P, W}\left(W^{2} s\right)$ is the power spectral density of $P_{W}$ and $S_{P, D}\left(W^{2} s\right)$ is the spectral density of $P_{D, W}$, i.e., the hydropower due to the production discharge $D_{W}$ for balancing wind power. Furthermore, we can relate the volumetric discharge demand $D_{W}\left(\mathrm{~m}^{3} / \mathrm{s}\right)$ due to wind power fluctuations by considering that $P_{D, i}=\eta_{i} \rho g h_{f, i} D_{W, i}$, where $\eta=$ efficiency $(-), \rho=$ water density $\left(\mathrm{kg} / \mathrm{m}^{3}\right), g=$ acceleration due 
to gravity $\left(\mathrm{m} / \mathrm{s}^{2}\right)$ and $h_{f}=$ effective fall height for the sum of the power stations that the considered demand flow is passing $(\mathrm{m})$. Therefore, the transfer of the power demand

fluctuation to (volumetric) discharge fluctuations is given by

$$
S_{D, W, i}=\beta_{i} S_{P, W, i}
$$

where the spectral translation factor $\beta=\left(1 / \eta_{i} \rho g h_{f, i}\right)^{2}$ was determined individually for the runoff of each of the sub-watershed $i$ as the sum of the fall heights $h_{\mathrm{f}, \mathrm{i}}$ at all the hydropower stations that the runoff from sub-watershed $\mathrm{i}$ is passing. The efficiency factor was taken as the ratio of the actual production for the entire Swedish hydropower system as reported by the Swedish Energy Authority (65.5 TWh/y) to the full potential for power production without consideration of power limitations $(79 \mathrm{TWh} / \mathrm{y})$, which was found to be $\eta=0.818$.

The demand discharge can be considered to consist of two components as in the following expression: $D_{i}=D_{B, i,}+D_{W, i}$, where $D_{B, i}$ is the production discharge of a hydropower base production. However, here the regulation related to the hydropower base production is neglected in the reference case analyzed in this study, i.e., $\mathrm{S}_{\mathrm{D}, \mathrm{i}}=\mathrm{S}_{\mathrm{D}, \mathrm{W}, \mathrm{i}}$.

Two approaches were used to express the demand spectrum $S_{D, W}$; the first is based on Eqn. (11) and the future wind power scenarios presented by Olauson and Bergqvist (2015) and the second reflects the coherence between the wind and water availability. For the first approach, we used the scenarios denoted A1, B1 and C1, which correspond to 20, 30 and $50 \mathrm{TWh} / \mathrm{y}$ of wind power (Table 1), and assumed that the regulatory demand is distributed on the different sub-watersheds by their available DRV according to

$S_{P, W, i}=\frac{V_{D R V, i}}{\sum_{i=1}^{303} V_{D R V, i}} S_{P, W, T o t}$

These scenarios (A1, B1 and C1) were presented by Olausson and Bergqvist (2015) and Olausson et al. (2016) and selected from those discussed in Section 2.1. Eqn. (12) means that the power spectral density of the total wind power production for a scenario $\mathrm{S}_{\mathrm{P}, \mathrm{W}, \mathrm{Tot}}$ is distributed on the individual sub-watersheds. The combination of Eqns. (11) and (12) 
translates to the power spectral density of the demanded production discharge in hydropower to balance the fluctuating wind power. This weighting implies that the fluctuation of the total wind power is balanced by hydropower production without linking the wind power and hydropower plants to the same geographical region.

The second approach denoted the runoff-wind proportionality approach assumes that the spectral demand density $D_{W, i}$ is proportional to the square root of the coherence spectrum between runoff (water availability) and geostrophic wind

$S_{D, W, i}=A_{W} \sqrt{C_{r, W}} S_{q, i}$

in which the coherence spectrum $C_{r, W}=\left|S_{r, W}\right|^{2} / S_{r} S_{W}, S_{W}=$ power spectrum density of the geostrophic wind energy (see Section 2.1), $S_{r, W}=$ cross-spectrum density between the runoff and geostrophic wind energy, and the coefficient $A_{w}$ depends on the actual variance in the wind power and is evaluated from the scenarios of wind power production. Note that this approach does not consider the cross-spectrum in Eqn. (8), while the coherence spectrum is only used for reflecting the power spectral density in the inflow of water in the discharge demand spectrum due to wind power balancing. In this runoff-wind proportionality approach, the coherence spectrum is taken as a constant for the same reason as stated above, i.e., that fluctuation in wind power production is not necessarily linked to the same geographical region as the hydropower plants. By using $S_{q, i}=S_{r, i} S_{\psi, i}$ in Eqn. (3),

$\operatorname{Std}^{2}\left(V_{i}\left(T_{2}\right)\right)=\int_{T_{f}=T_{1}}^{T_{2}}\left(S_{r, i}\left(T_{f}\right) S_{\psi}+S_{D, W, i}\right) d T_{f}$

in which the demand spectrum is expressed by either a) Eqns. (11) - (12) using the scenarios A1, B1 or C1 (Table 1) or b) Eqn. (13) using the runoff-wind proportionality approach (Table 1). Therefore, combining Eqn. (14) with Eqns. (5) and (7) yields the relative reservoir volume demand as a function of the variance in the runoff and that in wind power in the form of

$R_{R V D, i}\left(T_{2}\right)=z_{p} \frac{\sqrt{\int_{T_{f}=T_{1}}^{T_{2}}\left(S_{r, i}\left(T_{f}\right) S_{\psi, i}\left(T_{f}\right)+S_{D, W, i}\left(T_{f}\right)\right) d T_{f}}}{V_{D R V, i}}$ 
where the second factor (the fraction) on the right-hand side of Eqn. (15) is the standardized relative $\mathrm{RVD}$, i.e., $\mathrm{R}_{\mathrm{S}-\mathrm{RVD}}$.

\section{Results}

\subsection{Historical experience in the regulatory needs of hydropower}

A recent study shows that the annual flux of potential energy through the surface water over all of Sweden varies from 173 to $260 \mathrm{TWh} / \mathrm{y}$; the coefficient of variation for the total surface is 0.08 , with a one-year moving average of 0.16 and a daily value of 1.46 (Wörman et al., 2017). Fig. 4a shows the running monthly and annual mean values of all the streaming water power in Sweden (blue curves) in comparison to the potential power production assessed herein at the 506 hydropower stations given by their fall height without the consideration of possible turbine or other limitations, such as minimum spillage. The streaming water power is defined as the total energy flux of the surface water without consideration of the efficiency of the hydropower system $(\eta=0.818)$, which includes the turbine efficiency, spillage and reservoir level fluctuations. The graph also presents the actual production as reported by the Swedish Energy Authority. This graph presents the first indication of the valuable feedback existing between climate fluctuations and the high variability that exists in water availability and its energy content over a spectrum of various time scales as well as water management. In particular, we can see that the running annual mean of the streaming water power falls short of the actual production for relatively long periods; for example, in the years of 1991, 1997 and 2003 - 2004. By defining the cumulative power drop as the integrated energy deficit from the difference between the actual production and available streaming water power at the power stations, we can quantify such a drop as a function of its duration during which part of the production is maintained by using the energy stored in the many reservoirs that are distributed in the 303 sub-watersheds (of the maximum 
1,001 sub-divisions used here). The cumulative power drop depends on its duration and the time window over which the running mean is performed. Fig. $4 \mathrm{~b}$ shows the power drop distribution of each period as a function of the average time window. The maximum power drop for the period of $1974-2013$ was less than $20 \mathrm{TWh} / \mathrm{y}$ but only existed for a duration of three months. The maximum energy storage in all reservoirs corresponds to approximately 32 TWh. This power drop diagram offers a basic description of the need for energy storage in hydropower reservoirs, which is an alternative and complement to the spectral approach primarily advocated here.

\subsection{Climate-driven regulatory needs of hydropower production}

The spectral approach presented in Sections 2.2 - 2.4 and particularly Eqns. (10) and (15) facilitates the derivations of key information for the regulatory constraints under certain climate-related scenarios. This is because of the periodic nature often found in climate systems, which can be expressed in the form of power spectra. For instance, the findings of Plaut et al. (1995) and Speich et al. (1995) indicate that there are dominating modes of variability in the temperature time series of Northern Europe of 5.2 and 7.7 years, which covary with the North Atlantic Oscillation (NAO) index. Recently, it has been shown that similar variations exist in the streaming water power all over Sweden, but the dominating periods were found to be biannual, 3.6 and 8 years (Wörman, et al., 2016). In particular, the latter mode of variability was explained by the variation in temperature and evapotranspiration and is likely the same as the 7.7-year peak found earlier. The identified modes of variability showed significant coherence with the climate indices, including the North Atlantic Oscillation (NAO), the Pacific Decadal Oscillation (PDO) and solar intensity indices, which implies that climate factors potentially play a significant role in defining longterm regulatory needs. The North Atlantic Oscillation is known to have different modes of 
variability in periods up to a year (Barnston and Livezey, 1987), which is of great importance to the planning of renewable energy systems (François, 2016). This study confirms these patterns in the available power of surface water and on modes of variation well beyond a year.

Fig. 5a shows the power spectral densities of the discharge at Fäggeby in Dalälven and Fig. 5b shows the coherence between the streaming water power and geostrophic wind velocity. The power spectral density shows a marked annual peak but also minor modes of variability for both shorter and longer periods. In particular, because the variance in storage related to reservoir inflows is the integral of the power spectral densities, according to Eqn. 2, the "fat" tail in the spectral density between 3 and 10 years or longer contributes to the major regulatory need, i.e., the area below the "fat" tail is relatively large in comparison to the shorter modes of variability. The high peaks in the coherence spectrum indicate that the assumption used for deriving the discharge demand spectrum related to wind power fluctuations, $S_{q, D, i}=0$, can be questioned. Therefore, Fig. 5c shows an approximation of the cross-spectrum between water inflow and the corresponding production discharge related to wind power balancing, where the latter time series was scaled with a mean value of $17 \%$ of the inflow, the percentage that corresponds to the current ratio of annual wind power to hydropower. This diagram shows that for certain periods there is a negative correlation between the water inflow and wind power, which is primarily reflected on an annual basis due to a low runoff and high wind intensity during the cold part of the year. Such crosscorrelations can be accounted for in Eqn. (8) and the negative values increase the $\mathrm{R}_{\mathrm{S}-\mathrm{RVD}}$ value. However, this study did not cover such scenarios and thus assumes that regulation of the wind power fluctuations is performed without consideration of the compensatory or amplifying effects of covarying hydropower. This assumption leads to conservative estimates of the reservoir volume demand in the case of negative cross-correlations. In practice, it can 
be difficult to fully utilize the covariance between the availability of wind energy and hydropower, which explains why this aspect can generally be neglected in reservoir volume demand assessments.

The climate-driven fluctuations in the potential energy of the surface water were compared with the regulatory capacity of the existing reservoir system by using Eqn. (10), in which a constant demand has been assumed. Fig. 6 shows the standardized relative RVD, i.e., reservoir volume variance divided by the dedicated reservoir volume, $R_{S-R V D}\left(T_{2}\right)$. The analyses were performed as follows: a) individually for 303 of the 1,001 sub-watersheds with national coverage, for which there were reservoir volumes in the downstream flow path to the sea (green curves); and b) for a single, coordinated (aggregated) hydropower system, with a common national runoff and a common DRV (red curve) $(N=1)$. The blue curve is the average $R_{S-R V D}\left(T_{2}\right)$ of the 303 individual curves weighted by their contribution to the total power of the individual sub-watersheds. The relationship between $R_{S-R V D}$ and the longest considered regulation period $\mathrm{T}_{2}$ is due to the basic formulation of volume variance, Eqn. (3), in which it is assumed that all periods shorter than $\mathrm{T}_{2}$ are accounted for in the regulation and all periods longer than $\mathrm{T}_{2}$ are neglected. As shown in the graph, the average standardized RVD (blue curve) is below one, i.e., $R_{S-R V D}<1$, for a little less than two months, i.e., $\mathrm{T}_{2}<$ 0.17 years, as an average of all the 303 sub-watersheds. This longest considered regulation period of the integration of Eqn. 10 can be conceived as a lower bound of the period limit because the approach to regulating the runoff independently (individually) neglects all possible coordination gains between the regulation volumes. Therefore, as an upper bound derived for a single coordinated hydropower system $(N=1)$, we find that the limiting period increases significantly up to several years. The non-standardized $\left(z_{p} \neq 1\right)$ relative RVD of the storage volume that is permitted depends on the quantiles of the storage distribution associated with a certain exceedance probability (Eqn. (6)). If the probability of exceedance 
is lowered from $31.7 \%$ to $1 \%$, the period limit (corresponding to $R_{R V D}=1$ ), on average for the 303 sub- watersheds, decreases from 2 months to approximately 1 month. For major hydropower-exploited rivers, such as the Lule and Dalälven Rivers, the period limit decreases from several years to below one year as the probability of exceedance decreases from $31.7 \%$ to $1 \%$.

\subsection{Effect of the watershed damping of runoff on the regulatory period limit}

As shown in Fig. 3, there is a significant damping of the discharge power spectral densities from the upstream, smaller sub-watersheds and the aggregated hydrograph response further downstream. This damping is partly due to the statistical smoothing that results from the different runoff travel times from various sub-watersheds (geomorphological dispersion), but it is also due to runoff from different watersheds for which the runoff correlation is less than one, the hydrodynamic diffusion (wave diffusion) that occurs within the sub-watersheds and, to some degree, along river channels (Åkesson et al., 2016; Zmijewski and Wörman, 2016). The solid blue curve in Fig. 6 shows the standardized variance in the storage as an average of the 303 sub-watersheds (506 hydropower stations) considering the watershed damping. The longest possible regulation period considered $T_{2}$ at the quantile level $z_{p}=1$ is 2.5 times longer if the watershed is accounted for (blue solid curve) compared to if this damping is neglected in the analysis (blue dashed curve). The watershed damping of the runoff as the discharge becomes inflow to the reservoirs can thus be conceived as additional regulatory capacity, which is essential to account for in analysis and planning.

\subsection{Regulatory needs related to balancing wind power using hydropower}

The analysis of the regulatory capacity of the Swedish reservoir system when the hydropower production is governed by balancing the demand from the fluctuating wind power production was performed for four baseline scenarios including the three scenarios A1 (20 TWh/y), B1 
(30 TWh/y) and C1 (50 TWh/y) as given by Olauson et al. (2015) (Table 1). These three scenarios were used to determine the coefficient $A_{w}$ in the runoff-wind proportionality approach and subsequently used to generalize the wind power up to a total annual production of $66 \mathrm{TWh} / \mathrm{y}$, i.e., approximately the same as the hydropower production (Table 1). The standardized reservoir variance was derived from Eqn. (11), in which the demand spectrum $\mathrm{S}_{\mathrm{D}, \mathrm{W}, \mathrm{i}}$ was determined from either a spectral analysis of the wind power time series suggested by Olauson et al. (2015) and using Eqns. (11) - (12) or, in the runoff-wind proportionality approach, by use of Eqn. (13). Fig. 7 shows the demand spectra generated as a sum of the 40 sub-watersheds within the Lule River Basin. In this figure, the red curves show the power spectral densities $S_{\mathrm{P}, \mathrm{W}}$ of the wind power production according to the scenarios $\mathrm{A} 1, \mathrm{~B} 1$ and C1 multiplied with the $\beta$-function. The blue curve is the power spectral densities of the damped reservoir inflows as a sum of the 40 sub-watersheds $S_{r} S$. The green curve represents the spectral demand density $\mathrm{S}_{\mathrm{D}, \mathrm{W}}$ according to the runoff-wind proportionality approach, Eqn. (13), with $A_{w}$ taken as 0.8 . The $A_{w}$ coefficient was evaluated by fitting the power spectral density $\mathrm{S}_{\mathrm{D}, \mathrm{W}}$ for the Lule River Basin according to Eqn. (13) and the corresponding description using Eqns. (11) - (12); $\mathrm{A}_{\mathrm{w}}=1.06510^{-3} \mathrm{P}_{\mathrm{W}}^{1.578}$, where $\mathrm{P}_{\mathrm{w}}$ is the total wind production expressed in TWh/y. Therefore, the green curve of Fig. 7 corresponds to $P_{w}=66$ TWh/y, which yields $\mathrm{A}_{\mathrm{w}}=0.8$.

For comparison, the solid blue curves in Figs. (6) and (8) are the same and are derived considering the watershed damping of runoff in the representation of the reservoir inflows, but with a constant demand $\left(S_{\mathrm{D}, \mathrm{W}}=0\right)$. When an additional demand spectrum is introduced in terms of that reflecting the balancing of wind power production, the $\mathrm{R}_{\mathrm{S}-\mathrm{RVD}}$-curve is significantly shifted to the left in the diagram (red and black curves). The shift, therefore, reflects a shortening of the longest possible regulation period considered. Note that the black and the red curves are derived from Eqn. (15) for a successive increase in the upper 
integration bound $T_{2}$. The longest possible regulation period considered $T_{2}$ at the quantile level $z_{p}=1$ and decreases from approximately 2.5 months to 1.5 months at $\mathrm{P}_{\mathrm{W}}=20 \mathrm{TWh} / \mathrm{y}$ and, further, to less than a month at $\mathrm{P}_{\mathrm{w}}=50 \mathrm{TWh} / \mathrm{y}$. The relative difference increases as the quantile level increases (and the exceedance probability decreases).

\section{Discussion of implications}

\section{Climate drivers as factors for storage limitations}

The forcing data used in the analysis of the standard storage interval are based on the daily hydro-climatic data of precipitation, river discharge, temperature and geographical information, which have been used as a basis for deriving a description of runoff for over half a century for all of Sweden (Wörman et al., 2017). Although the data provide a thorough understanding of climate impacts on hydropower variability over a relatively long time span, there is uncertainty regarding the extent that these statistics apply to the future for management purposes, particularly considering the expected climate warming and slightly higher runoff in Sweden (Gardelin et al., 2002). Historically, a periodic variation in solar intensity can be traced back to the mid-18th century (Wilson and Mordvinoc, 2003; Movahed et al., 2006). This variation in solar radiation, to some degree, is coherent with the energy variation of surface water (Wörman et al., 2017). Studies of the linear trends in river discharge changes over century-long periods generally indicate significant global changes (Milly et al., 2005; Blender and Fraedrich, 2006). Similar century-long decreasing trends in the mean discharge are also apparent in the discharge record for the Dalälven River during 1860 - 1960 (blue curve in Fig. 9).

However, while such (linear) trends might exist historically, in the future, the regulatory needs and capacity limits may depend on the spectrum of fluctuating components in the runoff and demand, as suggested by Eqn. (10). Pekárová et al. (2003) showed that the river 
discharge for several rivers in Europe have exhibited a fluctuating behavior for at least 200 years (Fig. 9). The studies of Pekárová et al. (2003) and Wörman et al. (2017) and the discharge record from the Dalälven River at Fäggeby (used in this study) indicate that there is a marked multi-annual variation in the water availability and streaming water power, which, to a certain extent, follow periodic patterns.

The power spectral approach proposed here generally identifies the multi-annual modes of variability in river discharge or the streaming water power by relatively shallow and diffuse peaks called "fat" tails (e.g., Fig. 5a). However, because the fat tails have a relatively large cumulative contribution to the right-hand side of Eqn. (3), the phenomenon represents a significant part of the long-term variance in reservoir storage and defines fluctuations in the hydro-climatic regimes for short-term reservoir management. The latter can be considered by deducing the "short-term" power spectra of runoff specifically for the hydro-climatic regimes in which these are inferred, assuming that such spectra vary continuously over time (cf. wavelet analysis).

\section{Watershed damping of runoff}

The water transit intervals through the watershed follow a wide distribution (McDonnel et al., 2010) that can be seen as a damping of the variance of the discharge or stage at the watershed effluence. A part of the damping occurs is because of hydraulic dispersion in streams and geomorphological dispersion that is due to the various flow path lengths as reflected in the catchment instantaneous unit hydrograph (IUH) (Rinaldo et al., 1991). The watershed dispersion introduces a damping of the runoff fluctuations from the outflow of minor subwatersheds to the reservoir inflows (Fig. 3), which significantly decreases the regulatory demand as discussed in Section 3.3. For demonstration purposes in this study, we used a common scaling function $S_{\psi}$ for all the sub-watersheds. However, a more thorough 
evaluation of the variation of its variation with location and management practices is needed to determine the exact contribution. Recently, Zmijewski and Wörman (2016) proposed a spectral approach that describes the effect of regulatory management (RM) and watershed damping (MD) on the scaling function $S_{\psi}$ in regulated river basins with multiple hydropower stations. By combining such a theoretical description of the scaling function, it should be possible to account for changes in management practice on the estimation of regulatory thresholds and, hence, to facilitate feedback to the regulatory practice, which allows for the development of novel resource hedging policy and strategies.

\section{Wind power balance}

The analysis of the regulatory capacity of the Swedish hydropower system for balancing fluctuating wind power production was performed for three wind power production scenarios ranging from $20-50 \mathrm{TWh} / \mathrm{y}$ and the wind proportionality approach was used to generate a wind power production of $66 \mathrm{TWh} / \mathrm{y}$, i.e., equal to the hydropower production (Fig. 8). The regulatory demand is distributed on the 303 sub-watersheds according to their DRV without attempts of a more complex distribution of the power demand spectrum. In the future, there is a need to investigate the importance of the spatial cross-spectra (between sub-watersheds) in the demand and runoff. However, the DRV approach assumes that the regulation is made independently for each sub-watershed, which prevents the "sharing" of dedicated regulatory volumes. Such sharing principles can be considered by accounting for the spatial crossspectra in the demand and runoff.

While the coefficient of variation in wind power is expected to decrease with the expansion of wind power development because of geographical spreading (cf. Table 1), there is a consistent shortening of the longest possible regulation period considered with increasing wind power. The decrease in storage capacity as a function of increasing regulation leads to a 
significant increase in the opportunity cost (or marginal value) of the stored water. Consequently, there is an economical and efficiency incentive to explore methods that assess and prolong the longest possible regulation period considered. An example is to increase the cooperation between sub-watersheds or increase the use of compensatory energy sources. The cooperation of water resources between sub-watersheds would require a "flexible" DRV in which the DRV is partially shared between sub-watersheds according to the covariance in runoff from different sub-watersheds; we encourage further research in this direction. Longterm compensatory energy sources, such as heat or nuclear power, are extensively used for decreasing both the short- and long-term regulatory need within hydropower. Additionally, pump storage can be such a resource used for compensating certain regulatory needs related to balancing wind power using hydropower (Zhang, 2013). For example, if one assumes that the variance in the regulatory volume is zero for periods longer than $T_{2}$, and $S_{D, i}=S_{D, W, i}+$ $S_{D, C E}$, the use of Eqns. (3) and (11) yields $S_{q, i}+\beta S_{P, W}-\beta S_{P, C E}=0 ; T_{2}<T$, where the subscript CE denotes the compensatory energy production. The negative sign reflects the reduction of the regulatory demand due to compensatory energy sources. This relationship defines a compensatory strategy where the regulatory requirement on the hydropower system is statistically eliminated for periods longer than $\mathrm{T}_{2}$, but there is a possibility to define other compensatory energy productions, such as heat or nuclear power, in the form of $\mathrm{S}_{\mathrm{P}, \mathrm{CE}}$.

\section{Conclusions}

This study addresses the relationship between the climate-driven fluctuation in renewable energy availability and the fluctuating energy storage demand in hydropower reservoirs, which is analyzed using a spectral approach that statistically captures all temporal scales of the regulatory problem and incorporates spectral information on demand and energy availability. The spectral approach is developed for the estimation of the standardized relative reservoir volume demand (RVD) $\mathrm{R}_{\mathrm{S}-\mathrm{RVD}}$ as a function of the longest considered regulation 
period $\mathrm{T}_{2}$ and which is proposed as an alternative to conventional reservoir volume design. The $\mathrm{R}_{\mathrm{S}-\mathrm{RVD}}$ expresses the ratio between the volumetric storage need and dedicated reservoir volumes (DRV) that are identified in a system of water reservoirs along the downstream flow path for the runoff of individual sub-watersheds. Such dedication implies that the regulatory analysis is made independently for each watershed runoff and the associated DRV. The spectral decomposition of the reservoir design problem facilitates consideration of a continuous range of temporal scales of climate-driven fluctuations in energy availability and the assessment of implications for regulatory volume demands due to changes in the energy demand spectrum and the watershed runoff characteristics. The runoff characteristics can change, for example, due to successive land use changes or regulatory praxis changes in a watershed with multiple hydropower reservoirs. The standardized relative reservoir volume demand $\mathrm{R}_{\mathrm{S}-\mathrm{RVD}}$ is expressed for a constant demand by Eqn. (10) and for a demand spectrum, driven, e.g., by wind power balancing, by Eqn. (15). Fig. 6 shows $\mathrm{R}_{\mathrm{S}-\mathrm{RVD}}\left(\mathrm{T}_{2}\right)$ for a constant demand; however, the equation can account for any demand spectrum and watershed damping of the runoff. Fig. 8 accounts for a demand spectrum that reflects the balancing of various amounts of wind power production on a national spatial scale (represented by its power spectral density in Fig. 7).

An analysis was performed for the 303 selected sub-watersheds that covered the entire Swedish hydropower system and for which it was possible to determine the dedicated reservoir volumes (DRVs). The longest possible period considered for hydropower regulation was defined as the period $T_{2}$, which satisfied $R_{S-R V D}\left(T_{2}\right)=1$. The study shows that the climate-driven fluctuations of the surface runoff for a constant demand can be regulated with the longest possible regulation period considered or $\mathrm{T}_{2} \approx 2.5$ months as an average for the entire hydropower system given at the quantile level $\mathrm{z}_{\mathrm{p}}=1$ (an exceedance probability of $31.73 \%$ ). Individual hydropower-exploited rivers significantly exceeded this period, and the 
ensemble of $\mathrm{R}_{\mathrm{S}-\mathrm{RVD}}\left(\mathrm{T}_{2}\right)$-curves provide a relevant characterization for the support of management strategies. While it should be noted that the spectral analysis considers only the statistical behavior of the system, the approach facilitates a systematic consideration of changes in regulatory need, such as the introduction of a regulatory demand spectrum.

The balancing of wind power production by using hydropower significantly shortens the possible regulation period considered (Fig. 8). Here, we used the existing scenarios of wind power development in Sweden to demonstrate the regulatory capacity and limitation of the existing hydropower system for balancing fluctuations in the wind power production. The longest possible regulation period considered, $\mathrm{T}_{2}$, decreases from approximately 2.5 months to less than a month when the amount of wind power increases from 0 to $50 \mathrm{TWh} / \mathrm{y}$. This analysis assumes that all fluctuations are balanced precisely using the hydropower system without consideration of other regulatory needs or the compensatory effects of other energy sources on the electrical grid. While the study demonstrates a dramatic decrease in the available regulatory capacity for the balancing of fluctuating wind power production, it also shows that the spectral density of compensatory energy sources can reduce the regulatory need beyond the longest possible period possible considered for hydropower regulation. This compensatory power generation in the form of heat or nuclear power can be defined as a negative demand spectrum that prolongs the longest regulation period or fully cancels the need for hydropower regulations for periods longer than $T_{2}$.

A particular finding of the study is that the damping of the runoff to the reservoir inflow is due to in-stream, hydraulic and geomorphological dispersion significantly reducing the variance in the regulatory need. The system average regulation period $T_{2}$ was found to increase by a factor of 2.5 from approximately a month to 2.5 months because of such watershed damping (Fig. 6). 


\section{Acknowledgments}

We would like to thank Anna-Lotta Söderberg for collecting the data and assisting with the data analyses. The authors are grateful for the funding provided by The Swedish Hydropower Centre (SVC) and The National Strategic Research Project STand UP for energy. Interested readers can access the data used in this paper by contacting the corresponding author.

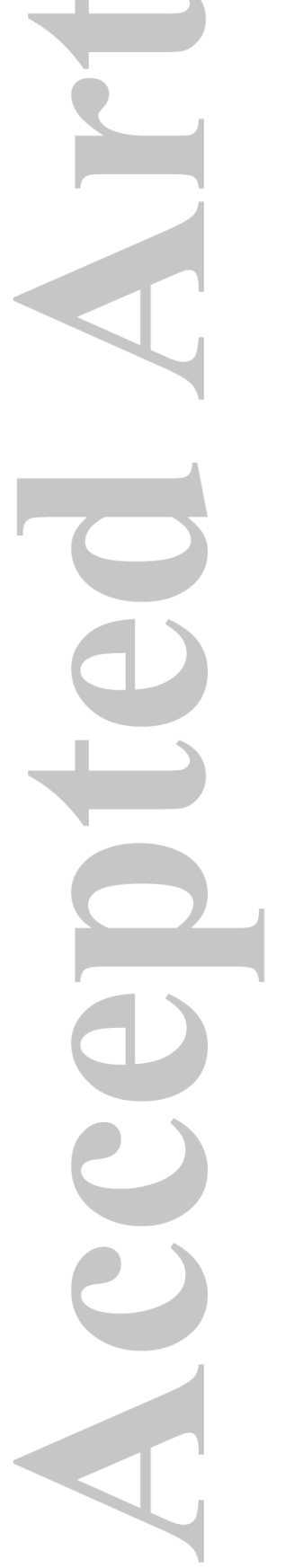




\section{References}

Åkesson, A., Wörman, A., Riml., J., Seibert, J., 2016. "Change in streamflow response in unregulated catchments in Sweden over the last century", Water Resources Research, 52(8): 5847 - 5867, DOI: 10.1002/2015WR018116

Barnston, R.E. Livezey, Classification, seasonality and persistence of low frequency atmospheric circulation patterns, Mon. Weather Rev. 115 (1987) 1083e1126.

Blender, R., Fraedich, K. Long-term memory of the hydrological cycle and river runoff in China in a high-resolution climate model, Int. J. Climatol, 26, 1547-1565 (2006)

Block, P. and Strzepek, K. (2010). "Economic Analysis of Large-Scale Upstream River Basin Development on the Blue Nile in Ethiopia Considering Transient Conditions, Climate Variability, and Climate Change." J. Water Resour. Plann. Manage., 10.1061/(ASCE)WR.1943-5452.0000022, 156-166.

Coulthard, T. J., Macklin, G.\& M. How sensitive are river systems to climate and land-use changes? A model-based evaluation. J. Quat. Sci. 16, 347-351 (2001)

Destouni, G., Fernando, J. \& Carmen, P. Hydroclimatic shifts driven by human water use for food and energy production. Nat. Clim. Change 3, 213-217 (2013)

Ely, C. R., D. J. Brayshaw, J. Methven, J. Cox, and O. Pearce (2013), Implications of the North Atlantic Oscillation for a UK-Norway Renewable power system, Energy Policy, 62, 1420-1427, doi:10.1016/j.enpol.2013.06.037.

Endegnanew, a. G., H. Farahmand, and D. Huertas-Hernando (2013), Frequency Quality in the Nordic Power System: Wind Variability, Hydro Power Pump Storage and Usage of HVDC Links, Energy Procedia, 35, 62-68, doi:10.1016/j.egypro.2013.07.159.

Farahmand, H., S. Jaehnert, T. Aigner, and D. Huertas-Hernando (2015), Nordic hydropower flexibility and transmission expansion to support integration of North European wind power, Wind Energy, 18(6), 1075-1103, doi:10.1002/we.1749. 
Fernandez, A. R., S. A. Blumsack, and P. M. Reed (2013), Operational constraints and hydrologic variability limit hydropower in supporting wind integration, Environ. Res. Lett., 8(2), 24037, doi:10.1088/1748-9326/8/2/024037.

François, B., 2016. Influence of winter North-Atlantic Oscillation on Climate-Related-Energy penetration in Europe. Renewable Energy, 99, pp.602-613.

Gardelin, M., Bergström, S., Carlsson, B., Graham, L.P. Lindström, G., 2002. Climate change and water resources in Sweden - analysis of uncertainties, Chapter: Climatic Change: Implications for the Hydrological Cycle and for Water Management, Volume 10 of the series Advances in Global Change Research pp 189-207

Geressu, R. T., and J. J. Harou (2015), Screening reservoir systems by considering the efficient trade-offs - informing infrastructure investment decisions on the Blue Nile, Environ. Res. Lett., 10(12), 125008, doi:10.1088/1748-9326/10/12/125008.

Gaupp, F., J. Hall, and S. Dadson (2015), The role of storage capacity in coping with intraand inter-annual water variability in large river basins, Environ. Res. Lett., 10(12), 125001, doi:10.1088/1748-9326/10/12/125001.

Giuliani, M., D. Anghileri, A. Castelletti, P. N. Vu, and R. Soncini-Sessa (2016), Large storage operations under climate change: expanding uncertainties and evolving tradeoffs, Environ. Res. Lett., 11(3), 35009, doi:10.1088/1748-9326/11/3/035009.

Guégan, M., Uvo, C. B. \& Madani, K. Developing a module for estimating climate warming effects on hydropower pricing in California. Energ. Policy 42, 261-271 (2012)

Hamadudu, B. \& Killingtveit, Å. Assessing climate change impacts on global hydropower. Energies 5, 305-322 (2012).

Jeuland, M., J. Baker, R. Bartlett, and G. Lacombe (2014), The costs of uncoordinated infrastructure management in multi-reservoir river basins, Environmental Research Letters, 9(10), 105006, doi:10.1088/1748-9326/9/10/105006. 
Korpås, M., Trötscher, T., Völler, S. \& Tande, J. O. Balancing of wind power variations using Norwegian hydro power. Wind Eng. 37, 79-96 (2013)

Lanini, J., Dozier, A., Furey, P., and Kampf, S. (2014). "Stochastic Method for Examining Vulnerability of Hydropower Generation and Reservoir Operations to Climate Change: Case Study of the Dworshak Reservoir in Idaho." J. Water Resour. Plann. Manage., 10.1061/(ASCE)WR.1943-5452.0000426, 05014004.

Loucks, D. P., E. van Beek, J. R. Stedinger, J. P. M. Dijkman, and M. T. Villars (2005), Water Resources Systems Planning and Management: An Introduction to Methods, Models and Applications, Paris : UNESCO.

McDonnell, J. J., et al. How old is streamwater? Open questions in catchment transit time conceptualization, modelling and analysis. Hydrol. Proc. 24, 1745-1754 (2010). DOI: 10.1002/hyp.7796.

Milly, P. C. D., Dunne, K. A. \& Vecchia, A. V. Global pattern of trends in streamflow and water availability in a changing climate. Nature 438, 347-350 (2005)

Movahed, M. S., Jafari, G. R., Ghasemi, F., Rahvar, S. \& Tabar, M. R. R. Multifractal detrended fluctuation analysis of sunspot time series. J. Stat. Mech. 2006, P02003 (2006) doi:10.1088/1742-5468/2006/02/P02003.

Olauson, J., and Bergkvist, M. (2015). "Modelling the Swedish wind power production using MERRA reanalysis data." Renewable Energy, 76, 717-725.

Olauson, J., Ayob, M.N., Bergkvist, M., Carpman, N., Castellucci, V., Goude, A., Lingfors, D., Waters, R., Widé, J., 2016. Net load variability in Nordic countries with a highly or fully renewable power system, Nature Energy, VOL 1 | DECEMBER 2016

Pekárová, P., Miklánek, P. \& Pekár, J., 2003. Spatial and temporal runoff oscillation analysis of the main rivers of the world during the 19th-20th centuries. J. Hydrol. 274, 62-79 
Plaut, G., Ghil, M. \& Vautard, R. Interannual and interdecadal variability in 335 years of central England temperatures. Science 268, 710-713 (1995)

Rinaldo, A., A. Marani, and R. Rigon (1991), Geomorphological Dispersion, Water Resources Research, 27(4), 513-525, doi: 10.1029/90wr02501.

Riml., J., Wörman, A., 2015. "Spatio-temporal decomposition of solute dispersion in watersheds", Water Resources Research, DOI: 10.1002/2014WR016385.

Rippl, W. (1883), The capacity of storage-reservoirs for water-slpply. (including plate)., Minutes of the Proceedings of the Institution of Civil Engineers, 71(1883), 270-278, doi:10.1680/imotp.1883.21797.

Suomalainen, K., G. Pritchard, B. Sharp, Z. Yuan, and G. Zakeri (2015), Correlation analysis on wind and hydro resources with electricity demand and prices in New Zealand, Appl. Energy, 137(0), 445-462, doi:10.1016/j.apenergy.2014.10.015.

Speich, S., Dijkstra, H. \& Ghil, M. Successive bifurcations in a shallow-water model, applied to the wind-driven ocean circulation. Nonlin. Proc. Geophys. 2 , 241-268 (1995)

Takeuchi, K. (1997), Least marginal environmental impact rule for reservoir development, Hydrological Sciences Journal, 42(4), 583-597, doi:10.1080/02626669709492055.

Thomas, H. A., Jr., and R. P. Burden (1963), Operations Research in Water Quality Management, pp. 1-17, Harvard Water Resour. Group, Cambridge, Mass.

US DOE, 2015. Wind Vision: A New Era for Wind Power in the United States. Report By U.S. Department of Energy. Assessed March 12, 2015: http://www.osti.gov/scitech

Vogel, R. M., and J. R. Stedinger (1987), Generalized storage-reliability-yield relationships, J. Hydrol., 89, 303-327.

Vogel, R. M. (1988), The value of stochastic stream flow models in over-year reservoir design applications, Water Resour. Res., 24(9),1483-1490. 
Willson, R. C. \& Mordvinov, A. V. Secular total solar irradiance trend during solar cycles 21-23. Geophys. Res. Lett. 30, 1199 (2003). doi:10.1029/2002GL016038.

Wern, L., Bärring, L., 2009. Sveriges vindklimat 1901-2008. Analys av förändring i geostrofisk vind. SMHI METEOROLOGI Nr 138/2009

Wörman, A., Lindström, G., Riml., J., 2017. The Power of Runoff. J. Hydrology, dx.doi.org/10.1016/j.jhydrol.2017.03.041

Zhang, N. et al., 2013. Planning Pumped Storage Capacity for Wind Power Integration. IEEE Transactions on Sustainable Energy, 4(2), pp.393-401.

Zmijewski, N., Wörman, A., 2016. "Hydrograph variances over different time-scales in hydropower production networks", Water Resources Research, 52(8):5829-5846, 10.1002/2015WR017775

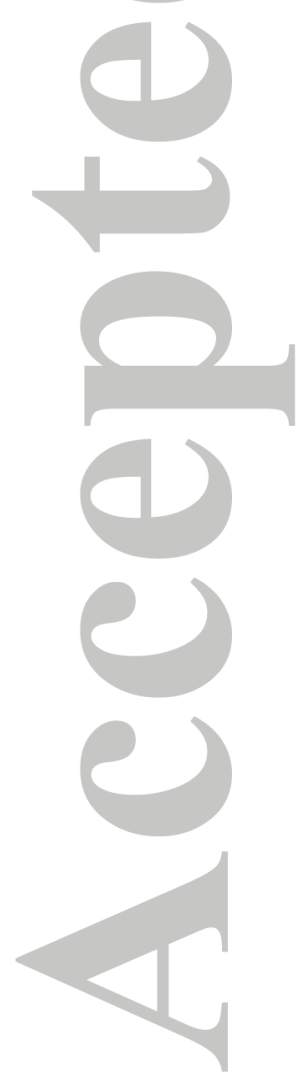


Table 1 Scenarios of wind power production schemes used to estimate the regulatory thresholds of the Swedish hydropower system. Scenarios A1, B1 and C1 are taken from Olauson et al. (2015) in which a stepwise expansion of individual wind energy converters (WECs) are assumed at the years 2000 , 2010 and 2020.

\begin{tabular}{|c|c|c|c|c|}
\hline Scenario & $\begin{array}{l}\text { Annual production ; } \\
\text { Mean power, } \boldsymbol{P}_{w, m}\end{array}$ & $\begin{array}{l}\text { Installed } \\
\text { capacity, } \\
P_{W, c}\end{array}$ & $\begin{array}{l}\text { Standard deviation } \\
\text { in hourely power ; } \\
\text { Ratio with } \boldsymbol{P}_{W, m}\end{array}$ & $\begin{array}{l}\text { Strategy of wind } \\
\text { power expansion }\end{array}$ \\
\hline $\begin{array}{l}\text { A1 } \\
\text { No off } \\
\text { shore }\end{array}$ & $20.1 \mathrm{TWh} / \mathrm{y} ; 2,294 \mathrm{MW}$ & $7,478 \mathrm{MW}$ & $1,399 \mathrm{MW} ; 61.0 \%$ & $\begin{array}{l}\text { Keep old WECs } \\
\text { built year } 2000 \text { or } \\
\text { later } \\
\text { Probability weight } \\
\text { north relative } \\
\text { south: } 0.8\end{array}$ \\
\hline $\begin{array}{l}\text { B1 } \\
5 \mathrm{TWh} / \mathrm{y} \\
\text { off shore }\end{array}$ & $30 \mathrm{TWh} / \mathrm{y} ; 3,425 \mathrm{MW}$ & $9,773 \mathrm{MW}$ & $1,881 \mathrm{MW} ; 54.9 \%$ & $\begin{array}{l}\text { Keep old WECs } \\
\text { built year } 2010 \text { or } \\
\text { later } \\
\text { Probability weight } \\
\text { north relative } \\
\text { south: } 0.8\end{array}$ \\
\hline $\begin{array}{l}\mathrm{C} 1 \\
13 \\
\mathrm{TWh} / \mathrm{y} \\
\text { off shore }\end{array}$ & $50 \mathrm{TWh} / \mathrm{y} ; 5,708 \mathrm{MW}$ & $14,231 \mathrm{MW}$ & $2,909 \mathrm{MW} ; 51.0 \%$ & $\begin{array}{l}\text { Keep old WECs } \\
\text { built year } 2020 \text { or } \\
\text { later } \\
\text { Probability weight } \\
\text { north relative } \\
\text { south: } 0.8\end{array}$ \\
\hline $\begin{array}{l}\text { Runoff- } \\
\text { wind } \\
\text { propor- } \\
\text { tionality } \\
\text { approach }\end{array}$ & $66 \mathrm{TWh} / \mathrm{y} ; 7,523 \mathrm{MW}$ & Not specified & Not specified & $\begin{array}{l}\text { Wind power } \\
\text { production follows } \\
\text { the intensity of } \\
\text { geostrophic wind }\end{array}$ \\
\hline
\end{tabular}


Figure 1.

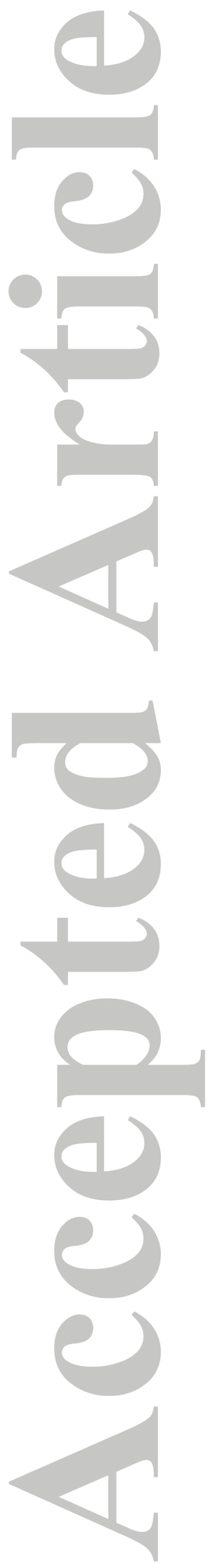

This article is protected by copyright. All rights reserved. 
Figure 2.

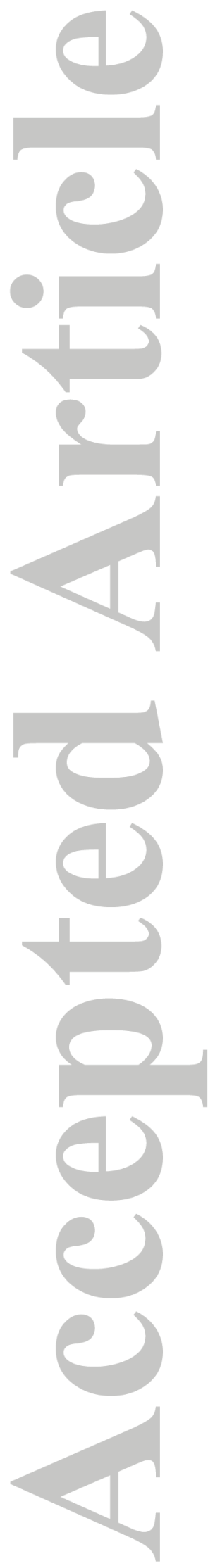

This article is protected by copyright. All rights reserved. 


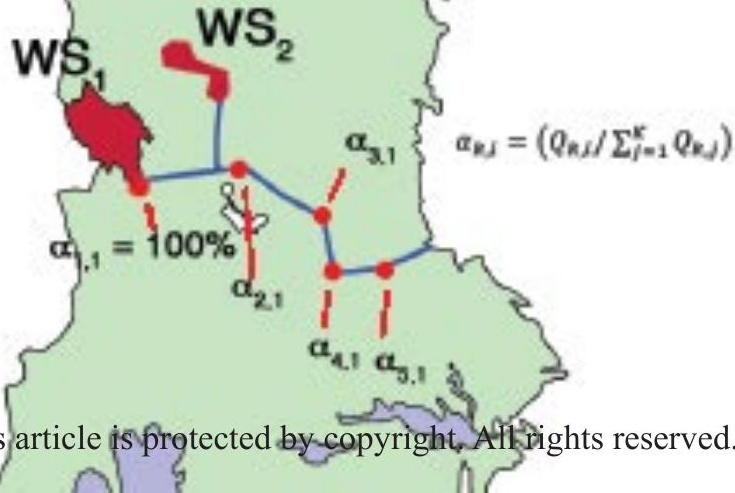


Figure 3.

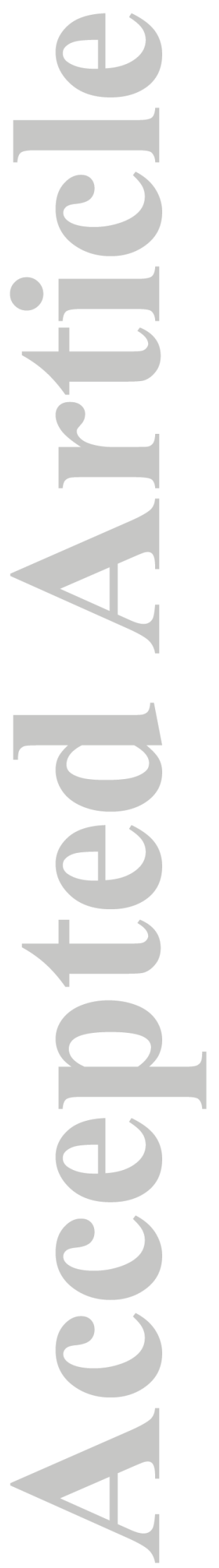

This article is protected by copyright. All rights reserved. 


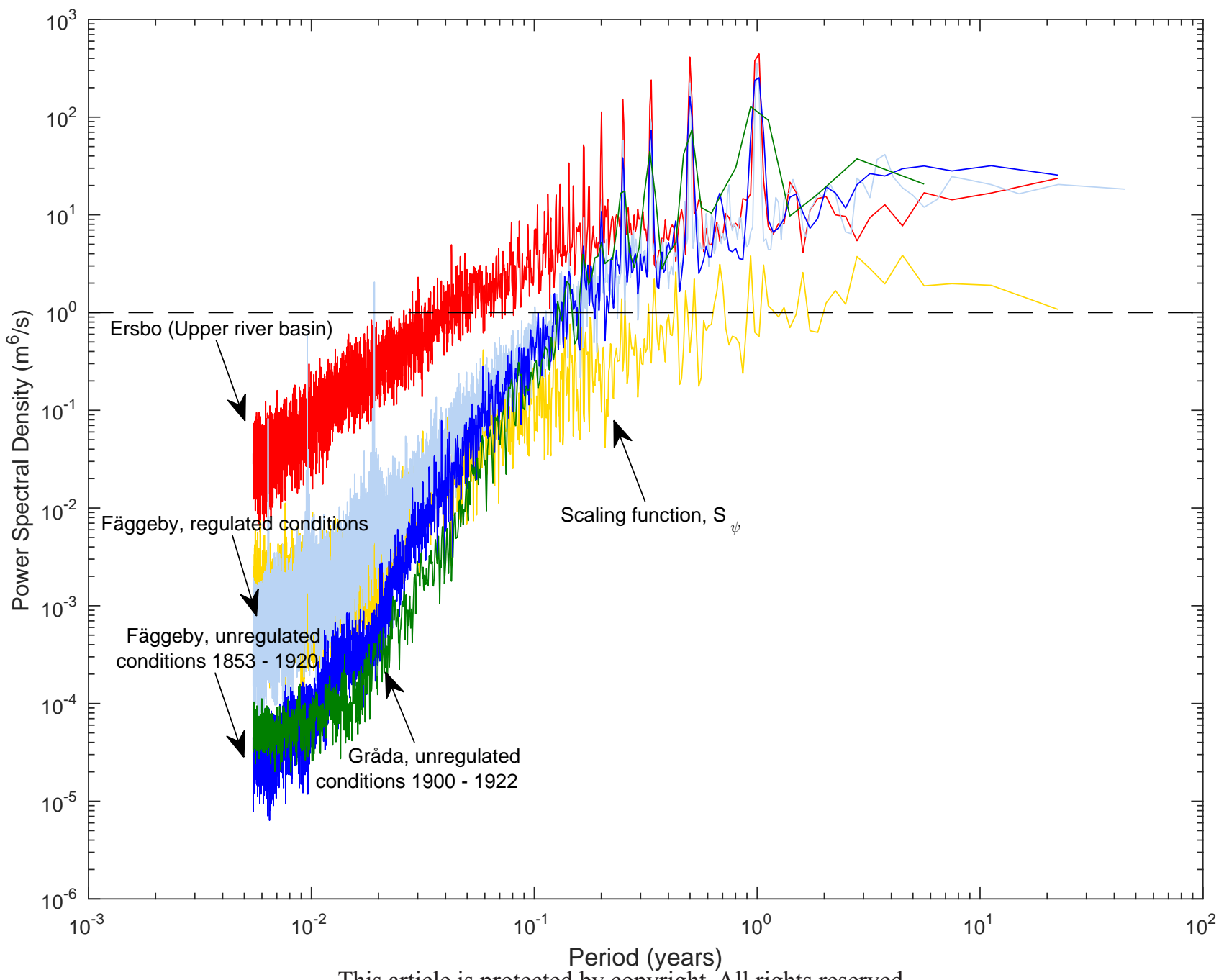

This article is protected by copyright. All rights reserved. 
Figure 4.

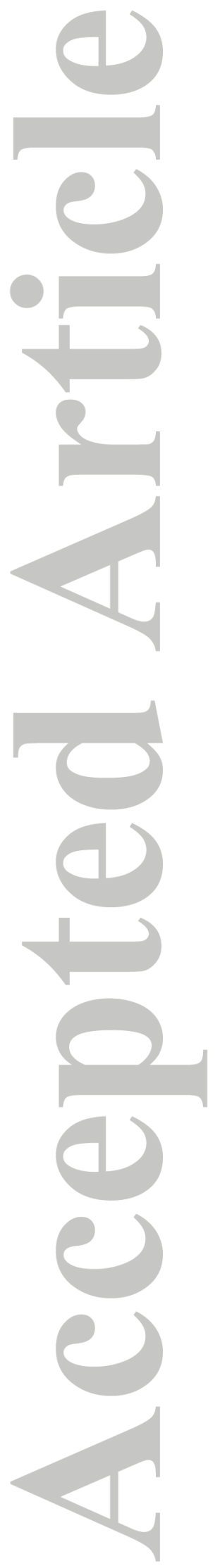

This article is protected by copyright. All rights reserved. 

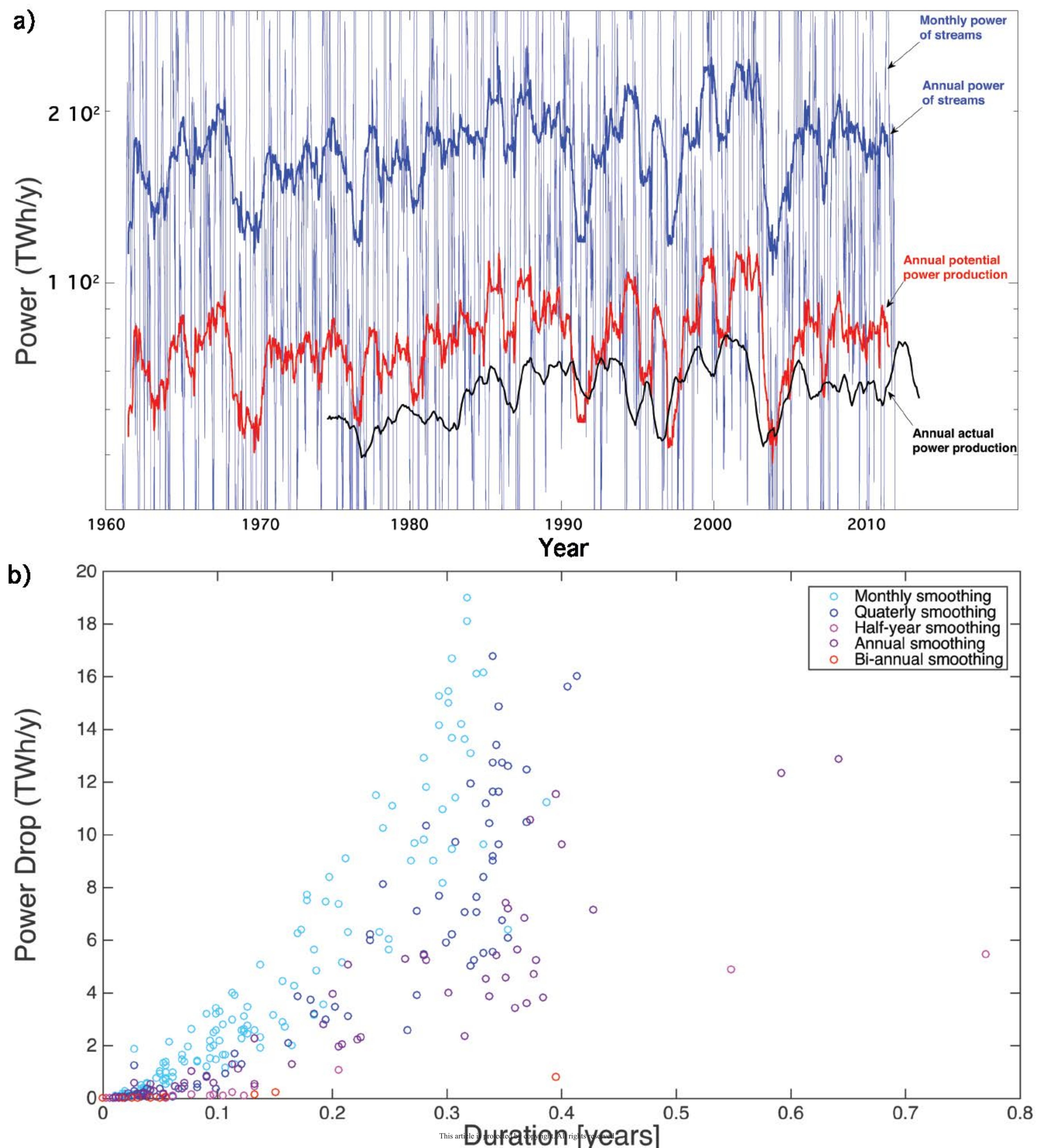
Figure 5.

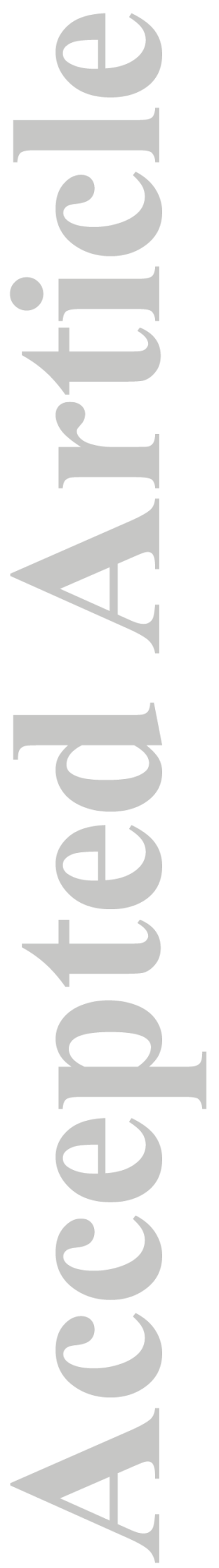

This article is protected by copyright. All rights reserved. 
a)

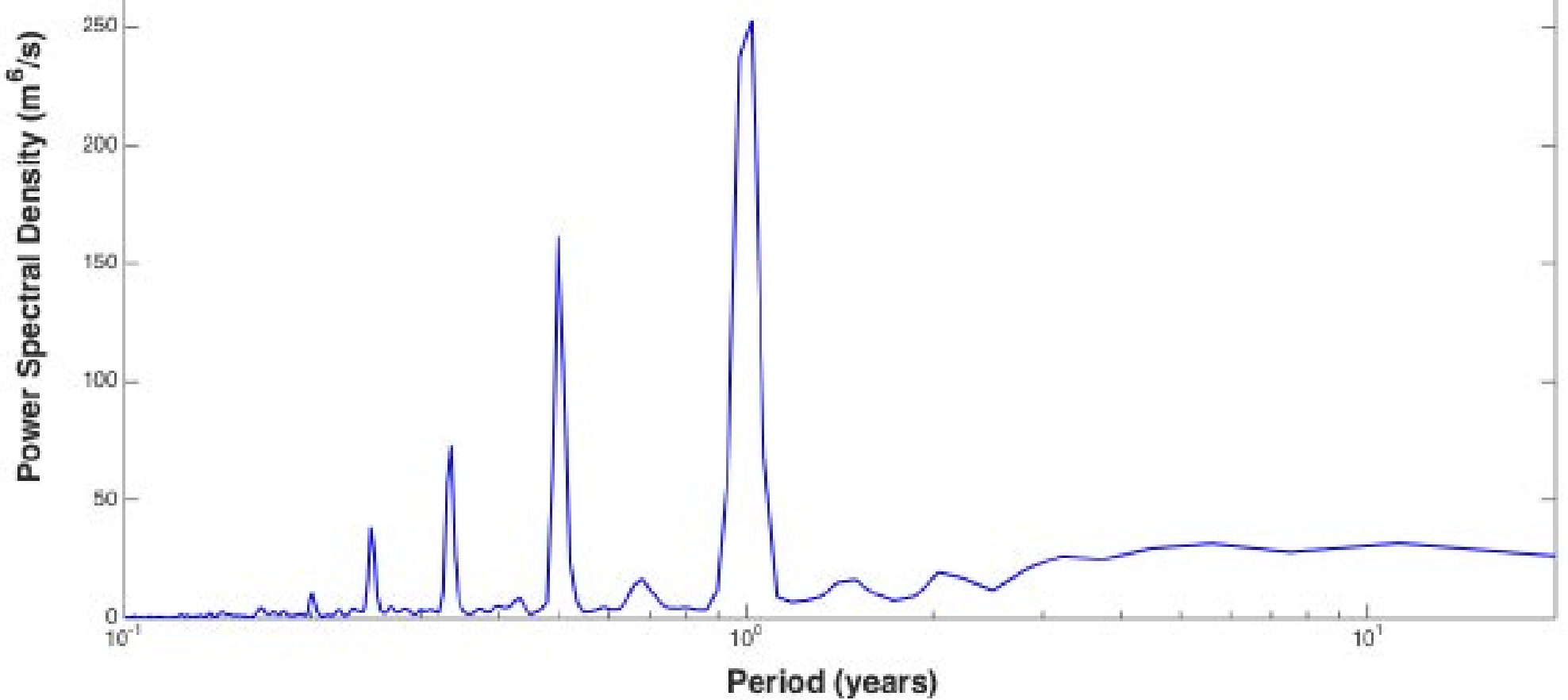

b)

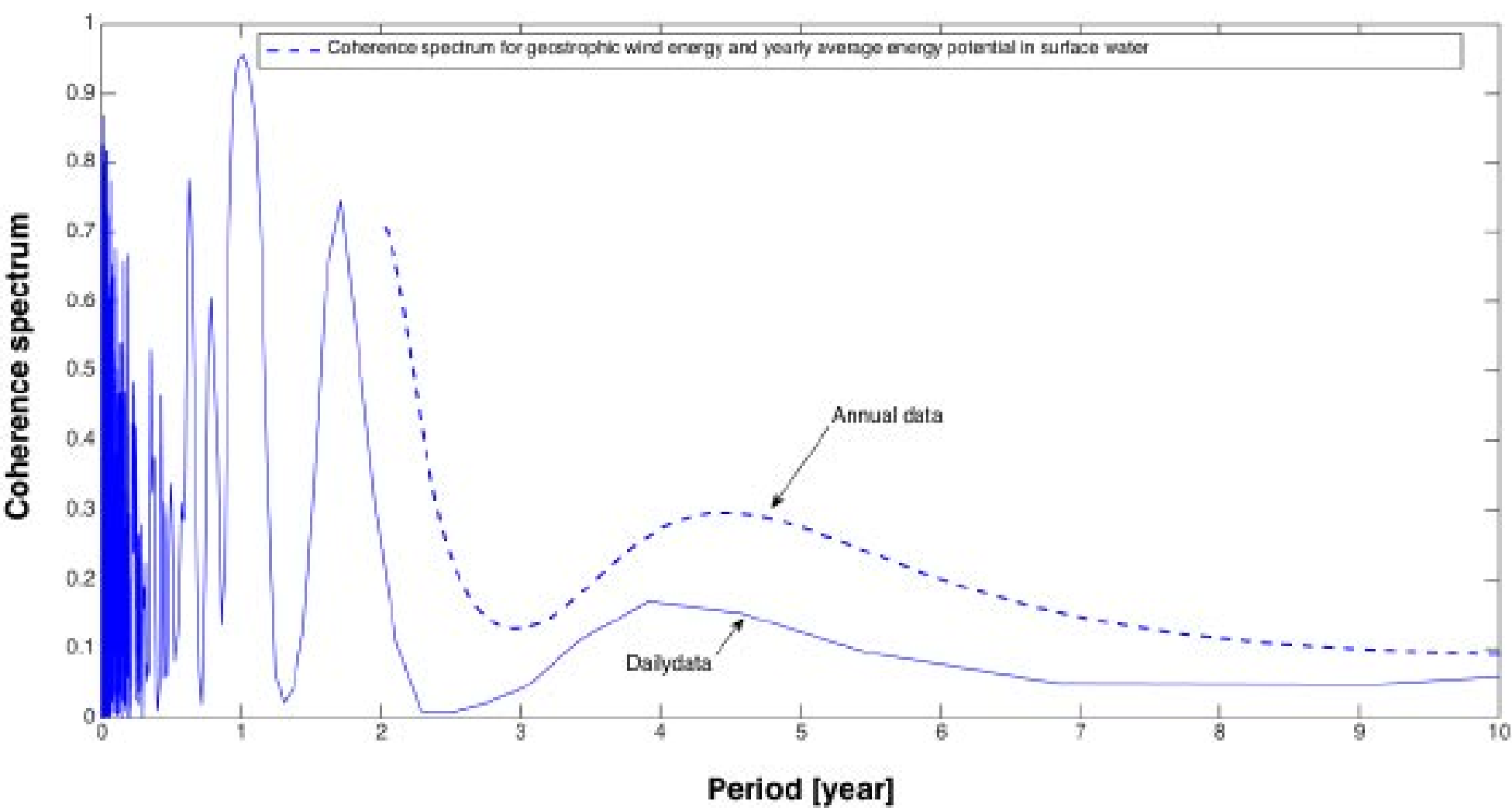

c)

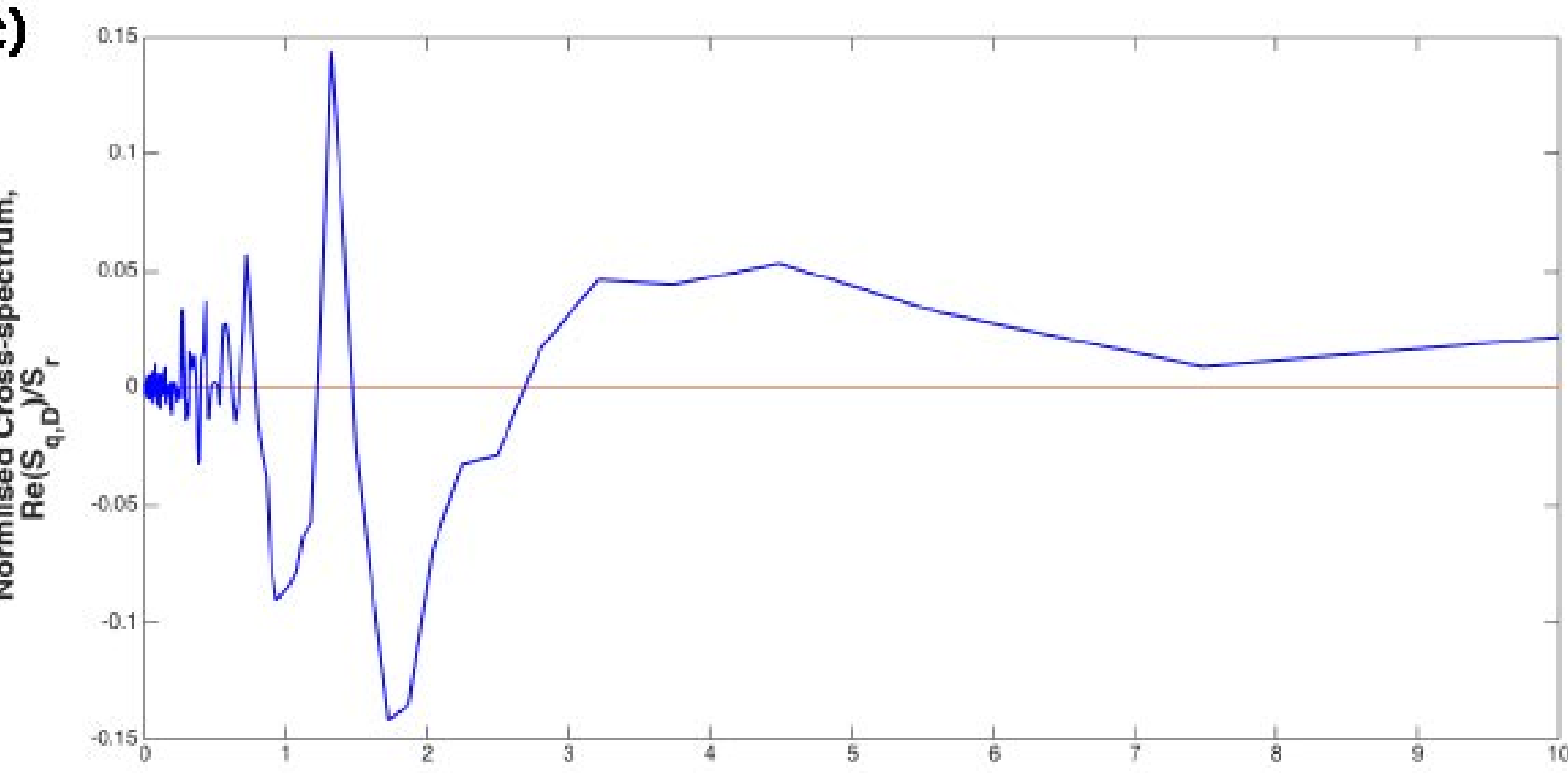

This article is protected by 
Figure 6.

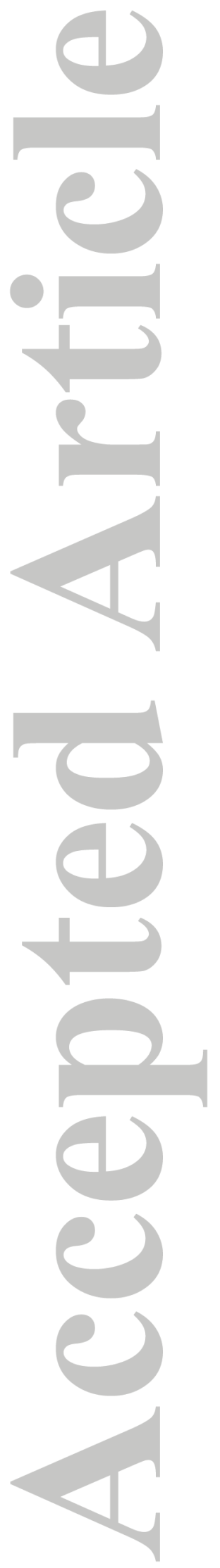

This article is protected by copyright. All rights reserved. 


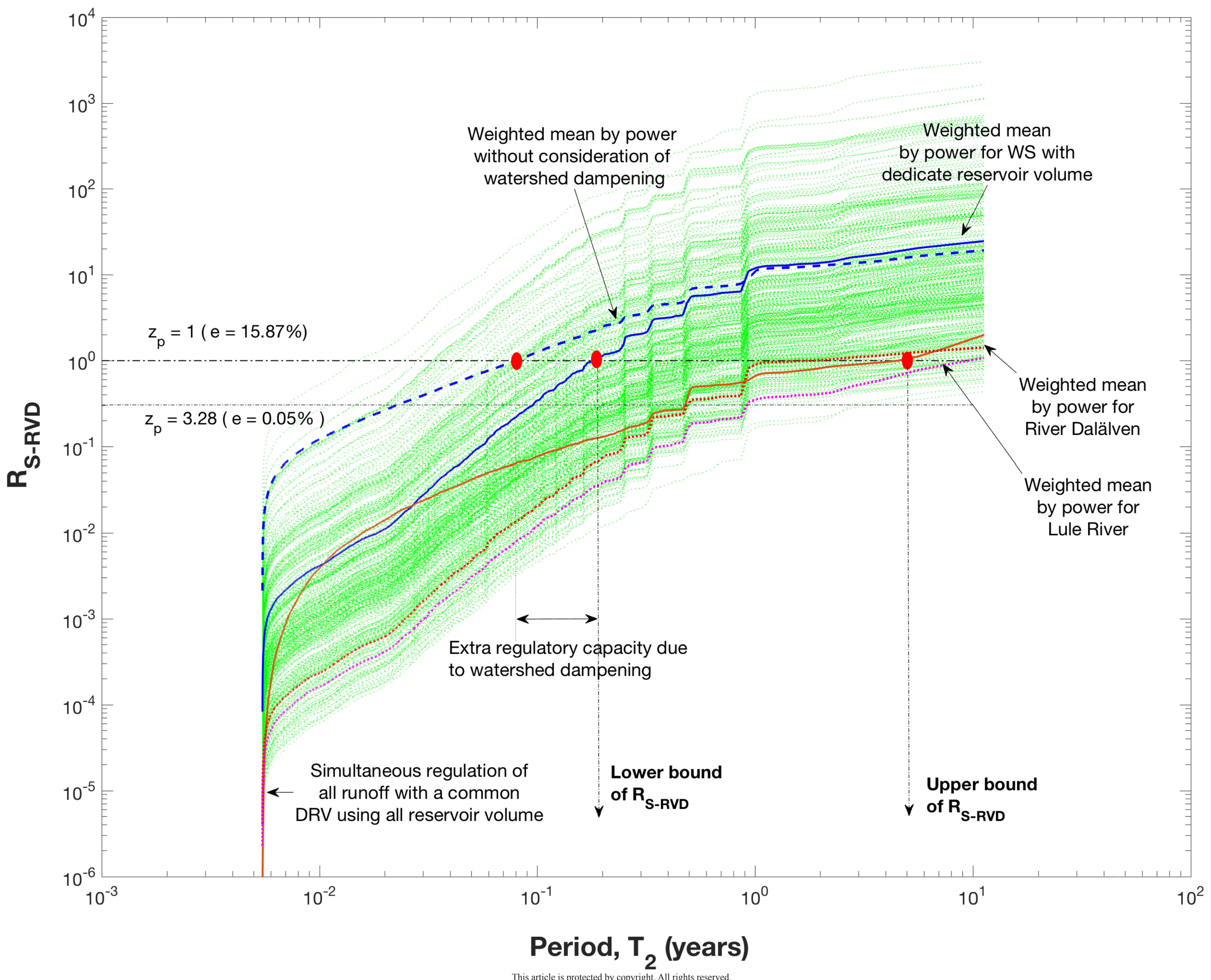


Figure 7.
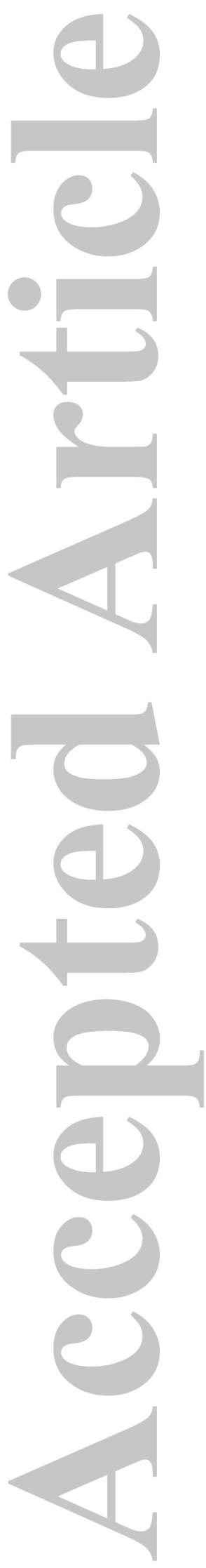

This article is protected by copyright. All rights reserved. 


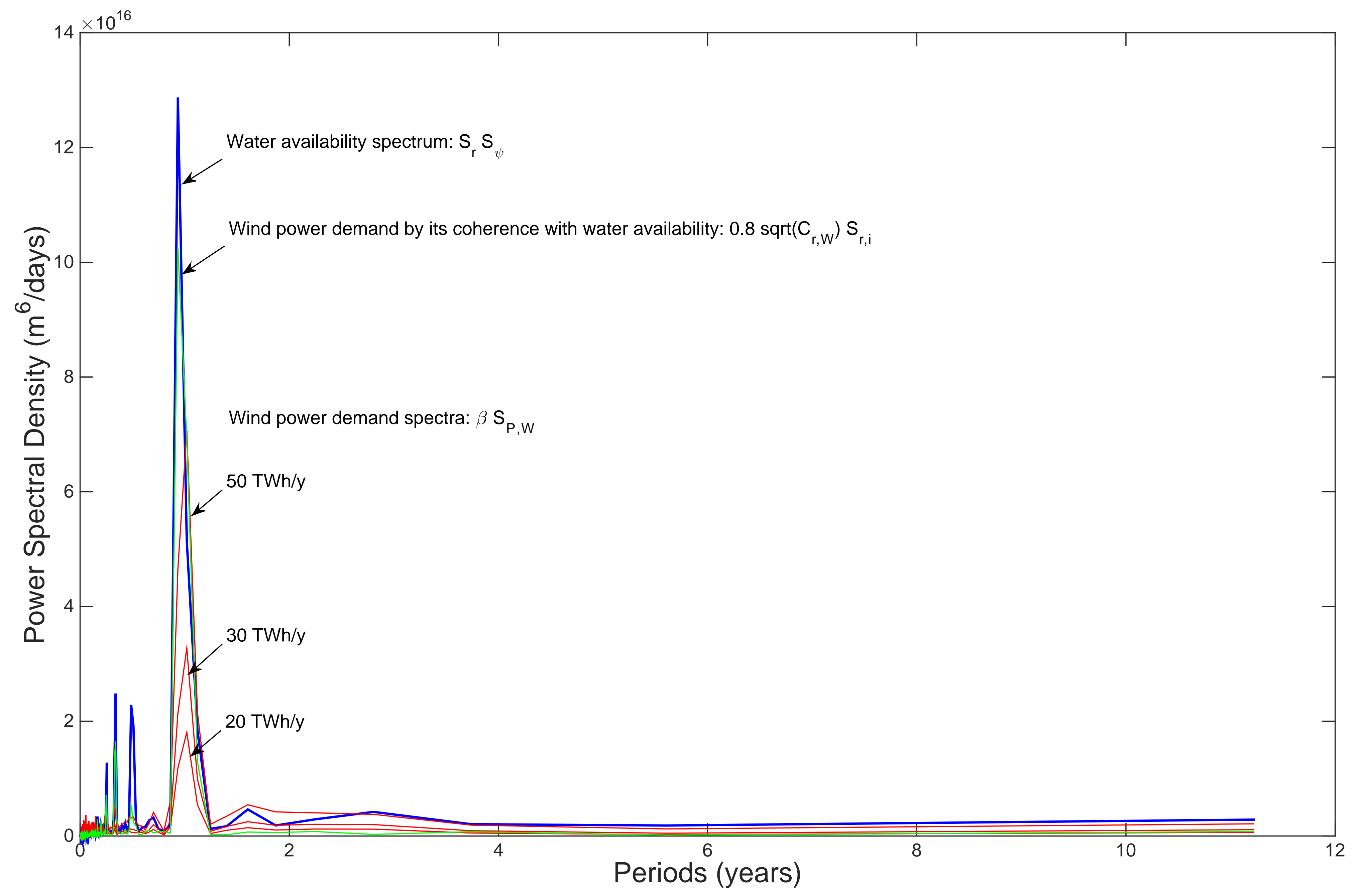


Figure 8.

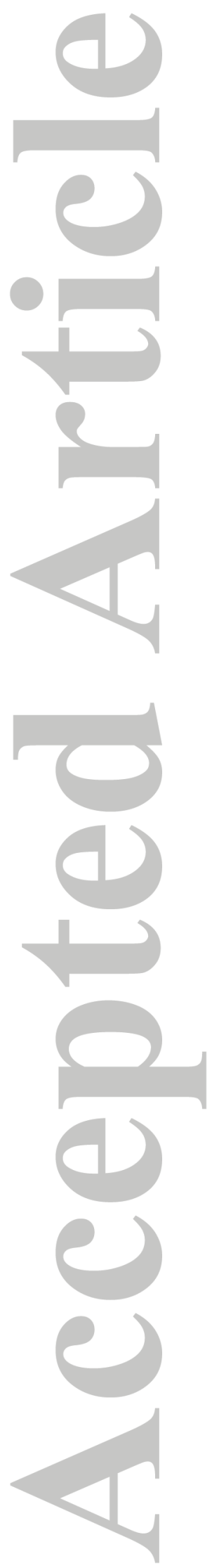

This article is protected by copyright. All rights reserved. 


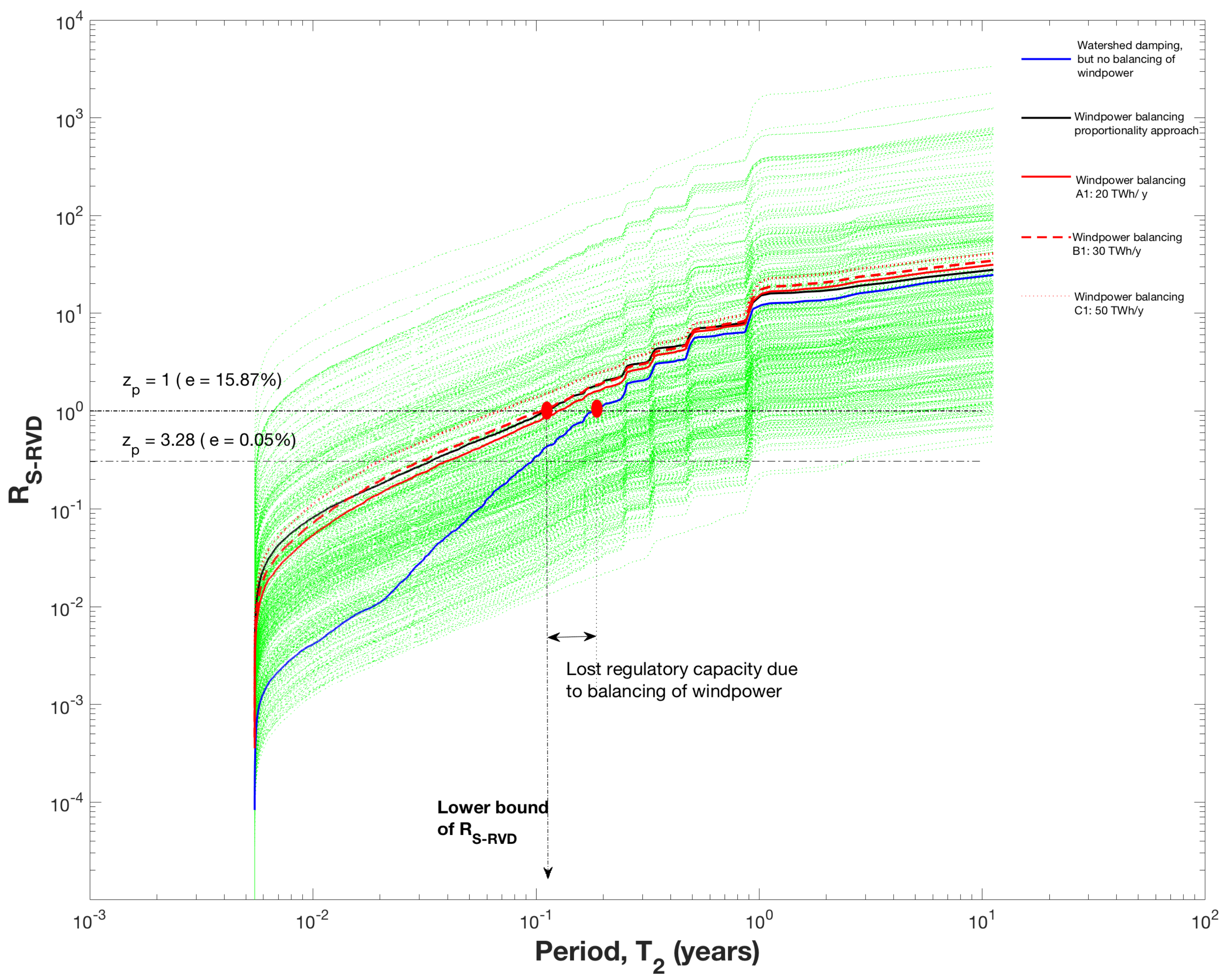

This article is protected by copyright. All rights reserved. 
Figure 9.

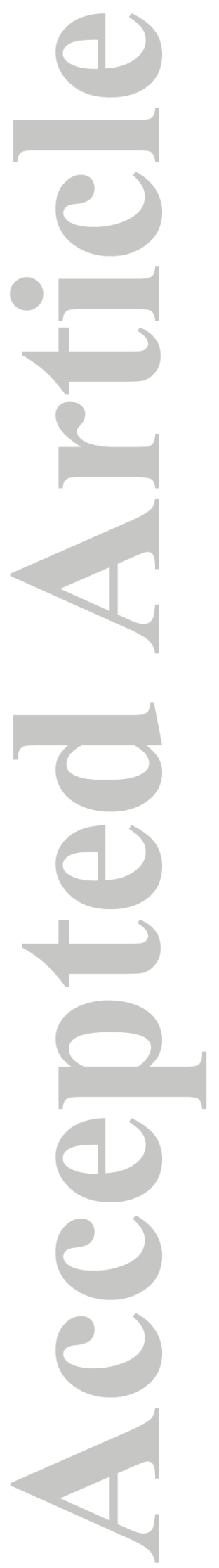

This article is protected by copyright. All rights reserved. 


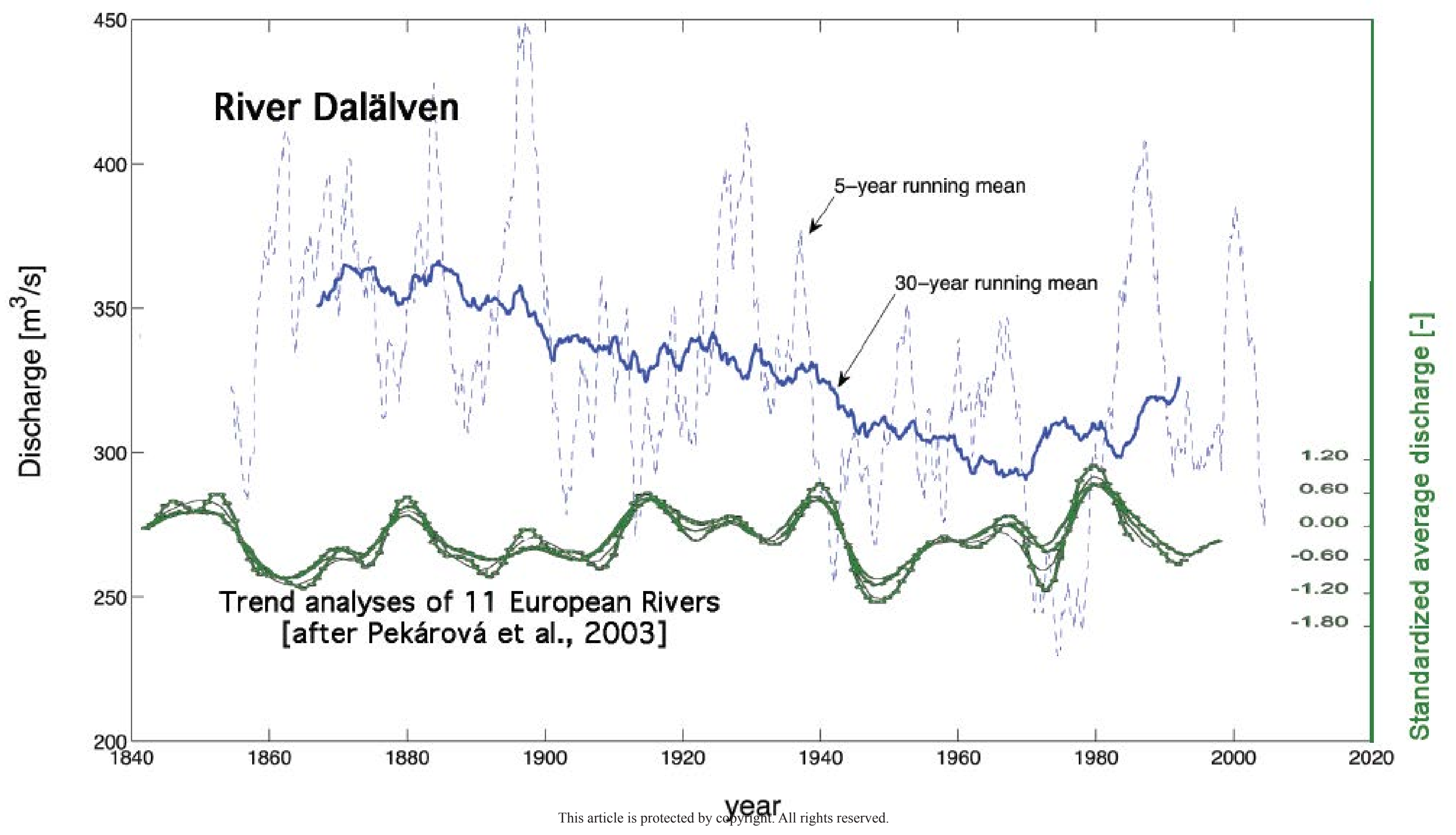

